\title{
La traducción de Ariel, de Sylvia Plath, al alemán: Los borradores del traductor como objeto de estudio
} Ariel, by Sylvia Plath, into German: The Translator's Drafts
as Research Focus

Itziar Hernández Rodilla

Universidad Complutense de Madrid

itzihern@ucm.es

Orcid: https://orcid.org/0000-0003-4163-1717

Recibido: 02/09/2021

Aceptado: 02/11/2021

DOl: https://dx.doi.org/10.12795/mAGAzin.2021.i29.03

\section{Resumen:}

Traducir puede tener el mismo significado que crear para autores que se mueven entre dos lenguas como Erich Fried, de origen vienés y residente en Inglaterra desde los 17 años, que escribió siempre en alemán, lengua a la que también tradujo numerosas obras, entre ellas Ariel, de Sylvia Plath.

Analizar las diversas versiones de un único proceso traslativo, desde el primer borrador hasta la versión definitiva -en este caso los borradores inéditos de la traducción de "Tulips" y "Fever $103^{\circ}$ " que Erich Fried realizó al alemán, tal y como se conservan en el archivo de la Biblioteca Nacional en Viena - puede proporcionar información extraordinaria sobre la introducción de nuevas ideas o formas artísticas en un marco lingüístico y cultural naturalmente diverso.

Palabras clave: Postraducción, versiones, Ariel, Sylvia Plath, reframing

\begin{abstract}
:
Translating can have the same meaning as creating for authors who move in between two languages, as Erich Fried, born and brought up in Vienna and emigrated at 17 to England, who always wrote in German. He also translated into German a whole series of works, among others, Ariel, by Sylvia Plath.

Studying the different versions of the same text in a sole translative process, from the first draft to the final version (through the unpublished drafts of "Tulips" and "Fever $103^{\circ}$ " translation into German by Erich Fried, as they are kept in the Vienna National Library) can give us extraordinary clues about the introduction of new ideas and artistic forms in a linguistic and cultural frame, different by nature.
\end{abstract}

Keywords: Posttranslation, versions, Ariel, Sylvia Plath, reframing 


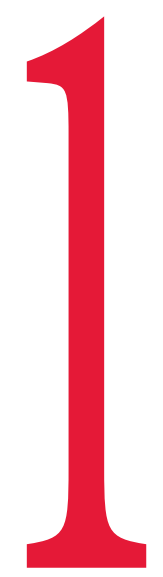

\section{Introducción}

Traducir puede tener el mismo significado que crear para autores que se mueven entre dos lenguas como Erich Fried, de origen vienés y residente en Inglaterra desde los 17 años y hasta el final de su vida, a lo largo de la cual escribió siempre en alemán, lengua a la que también tradujo numerosas obras, entre ellas alguna de Sylvia Plath.

Las diversas fases de escritura, traducción, reescritura y retraducción se pueden considerar, en tal caso, parte de un mismo «proceso circular» que potencia la creación poética y desdibuja las fronteras entre hecho traslativo y texto original.

Estudiar las diversas versiones de un texto - en este caso, la traducción de Ariel, de Sylvia Plath, al alemán - en un único proceso traslativo, desde el primer borrador hasta la versión definitiva, puede proporcionar extraordinarias pistas sobre la introducción de nuevas ideas o formas artísticas en un marco lingüístico y cultural naturalmente diverso. Y ofrece también una ventana al espacio sociopsicológico del público lector y a la forma en que se reciben las ideas traducidas en la cultura meta.

Mi intención es analizar estas cuestiones a través del estudio de los borradores inéditos de la traducción de los poemas «Tulips» y «Fever $103^{\circ}$ », del volumen Ariel, que Erich Fried realizó al alemán, tal y como se conservan en el archivo de la Biblioteca Nacional en Viena.

\section{Erich Fried, traductor}

\subsection{Breve apunte biográfico}

Nacido el 6 de mayo de 1921 en Viena como hijo único de una pareja judía, la Anexión alemana de Austria en 1938 convirtió a Erich Fried «de estudiante de secundaria austriaco en judío perseguido» ${ }^{1}$ (Fried 1981:21). Huyó a Londres. En el exilio inglés, colaboró con organizaciones alemanas y austriacas. Tras la guerra, trabajó como comentador en la BBC, cargo que abandonaría debido a la postura de la productora en cuanto a la Guerra Fría.

Con una personalidad muy política y enfrentada como judío a la postura de Israel, Fried escribió cantidades ingentes de poemas, ensayos y relatos (además de un libro de memorias, una novela, tres radiodramas y una obra de teatro), participó en innumerables conferencias, seminarios de discusión y actos de solidaridad. A lo largo de su intensa actividad política e intelectual, ganó enemigos por doquier y se vio salpicado por calumnias, censura y demandas judiciales. Su obra y su incansable compromiso fueron reconocidos solo muy tarde: ya superados los sesenta años y muy enfermo de cáncer. Recibió, entonces, importantes galardones literarios.

Igualmente fructífera sería su labor como traductor de autores como Dylan Thomas, T. S. Eliot y Sylvia Plath, entre otros poetas. Además de William Shakespeare, de quien tradujo veintisiete obras.

Murió el 22 de noviembre de 1988 y fue enterrado en Londres.

\subsection{Erich Fried como traductor}

En cuanto a sus razones para traducir, serían varias a lo largo de su vida. La primera, no profesional, la necesidad de entender mejor la literatura de su país de acogida, por la que sentía, como autor, una gran curiosidad. Más adelante, de hecho, afirmaría: «Traduciendo se aprende de todo, la verdad, pues ya solo la práctica de deber formular las cosas de forma precisa y responsable es algo que, más allá de mi actividad como traductor, se ha establecido como costumbre» (Rothschild 1986: 20).

El despegue de Fried como traductor se debe a su versión de la obra Under Milk Wood, de Dylan Thomas, cuyas buenas críticas permitieron que la editorial Suhrkamp lo contratase como traductor.

«De golpe, me hice conocido como traductor de textos difíciles y recibía mas ofertas interesantes de las que podía aceptar. Siguieron otros cuatro libros de Dylan Thomas, un divertimento poético de Lawrie Lee y dos piezas en verso de T. S. Eliot, entre otras. Tuve que limitarme a aceptar ofertas interesantes desde el punto de

(1) Todas las traducciones de las palabras de Fried son propias. También lo son las traducciones de citas de otros idiomas que se han reproducido directamente en español. 
vista literario», diría el propio Fried (1988: 148). A su legado como traductor, se unirían con el tiempo también las veintisiete obras de Shakespeare que tradujo en total.

Sería la editorial Suhrkamp la que publicaría también su traducción de Ariel, en una edición bilingüe, en 1974. No existe hasta el momento en lengua alemana ninguna otra traducción de los poemas de Sylvia Plath (pese a las malas críticas recogidas por la versión existente), un dato que parece digno de mención dadas las más de cuatro décadas de edad con que cuenta la traducción de Erich Fried.

\section{La obra: Ariel, de Sylvia Plath}

En el New York Times Book Review del 5 de noviembre de 2000, Joyce Carol Oates contaba a Sylvia Plath entre «los poetas de posguerra anglosajones más celebrados y controvertidos» (Oates 2000).

No cabe duda de que Plath está entre los poetas más dinámicos y admirados del siglo xx. Más allá de la indudable calidad literaria de la autora, lo cierto es que Sylvia Plath es un mito que continúa fascinando a lectores y editores. Lo que la ha convertido en icono es posiblemente la modernidad de su historia personal. Puede que fuese un genio, pero se hacía las mismas preguntas que todas las mujeres: ¿voy a ser yo o voy a ser madre? ¿Voy a ser yo o voy a ser esposa?

Para cuando se quitó la vida en febrero de 1963, había publicado un único volumen de poesía, The Colossus (Heinemann, 1960), y su novela, ya de culto, The Bell Jar (Heinemann, 1963). Su segundo libro de poemas, Ariel (Faber\&Faber), se publicó en 1965; sus Collected Poems (Harper\&Row) ganaron el Pulitzer en 1982. Estos dos últimos libros los editó, en realidad, Ted Hughes, poeta británico tan famoso por su poesía como por su atormentado matrimonio con Plath.

Es, de hecho, la muerte de la poeta tan joven, en unas circunstancias verdaderamente dramáticas como consecuencia de su ruptura con Hughes, lo que la convirtió en una mártir del feminismo en los setenta y lo que la elevó a la categoría de leyenda.

No se niega con ello que fuese una poeta excelente. Bien pudo ser su suicidio tan joven lo que la elevase a la fama, pero los mejores poemas de Plath, muchos de los cuales datan de las últimas semanas tan turbulentas de su vida y se recogen en Ariel, parecen «cincelados, con un fino instrumento quirúrgico, en la frialdad del hielo ártico» (Oates 2000). Sus versos se muestran como un catálogo de la desesperación, las emociones violentas y la obsesión con la muerte.

Intensamente autobiográfica, la poesía de Plath explora su propia angustia, los altibajos de su relación con Ted Hughes y los conflictos irresueltos con sus padres, así como la visión que tenía de sí misma. Su lenguaje es tenso y original; sus estrategias, elípticas; sus sentimientos, auténticos: dolor, desconcierto, rabia, estoicismo, amarga resignación.

Thomas McClanahan (1980: 92) diría que los poemas de Ariel «son testimonios personales de la soledad y la inseguridad que sufría Plath [...] En Ariel los incidentes diarios de la vida se transforman en horribles experiencias mentales de la poeta».

Si bien todos los poemas de Ariel son un legado de dolor, miedo, depresión traumática y deseo de autoaniquilación, algunos de los más conocidos, entre ellos «Daddy», se refieren a la atormentada relación que Plath tenía con su autoritario padre y a su sensación de abandono cuando él murió.

Aunque posiblemente sea este el más famoso de los poemas de Plath, se ha renunciado a su análisis dada la insatisfacción que Fried sentía por su traducción — por lo demás, excelente, en opinión de quien escribe y de los críticos de la época (Vordtriede 1974), que no dudaron en criticar la traducción en otros aspectos-, tal y como se refleja en la nota que añade a la obra publicada en alemán: «Papi (pp. 106/107) Este poema es, en mi opinión, intraducible. El texto alemán es solo un intento de transmitir una sensación similar» (Fried 2016 [1974]: 176). No nos resistimos a añadir: ¿y no es, al fin y al cabo, eso cualquier traducción? En todo caso, decimos, no trataremos dicho poema.

Hay otro tema del que Plath parece escribir con igual fervor: la enfermedad. Repetidos hasta la infinidad en sus diarios, los síntomas físicos de resfriados, fiebres, náuseas y calambres se abren paso hasta la poesía. Quizá porque, como Tom Hughes (1970: 187) dijo: «Sus elementos eran extremos: un espíritu violento casi demoniaco, 
enfrentado a su ternura y su capacidad de sufrir y amar las cosas infinitamente, que era igual de grande y mucho más evidente. [...] Veía el mundo en la llama de la sustancia última y la profundidad última». Era, decía, como una clarividente usando sus poderes psíquicos para describir el mundo.

De la enfermedad tratan, precisamente, los poemas elegidos para este análisis: «Tulips» y «Fever $103^{\circ}$ ». Si se han elegido estos no ha sido solamente por el tema, sino también porque reflejan, como se verá, los procesos de corrección y recorrección de Fried, que conserva o vuelve a lo largo del proceso a decisiones anteriores.

\section{1. «Tulips» $\mathrm{y}$ «Fever $1 \mathbf{1 0 3}^{\circ} »$}

En marzo de 1961, Sylvia Plath fue hospitalizada por una operación de apendicitis, poco antes de la cual había tenido un aborto. Plath escribió «Tulips», un poema casi tan conocido como «Daddy», el 18 de marzo, sobre un ramo de tulipanes que había recibido durante su convalecencia de la operación. Compuesto por nueve estrofas de siete versos, el poema refleja la tensión entre el deseo de la poeta de una muerte sencilla y el impulso de vivir que suponen los tulipanes. La narradora aprecia la blancura y la esterilidad de la habitación de hospital porque le permiten hacer caso omiso de las complicaciones y el dolor de la vida. Pero los tulipanes, que para ella son excitabilidad, jadeos y ojos que la miran mientras descansa, la obligan a reconocer su vitalidad. Considera, no obstante, que son peligrosos y atractivos como un tigre y los acusa de consumir su oxígeno.

«Fever $103^{\circ}$ », por su parte, describe el delirio de la fiebre alta. Las olas de calor se describen con una serie de metáforas, que comparan el estado febril con un viaje al infierno debido a los pecados, al comportamiento impuro. Algunas de dichas metáforas son tradicionales y mitológicas, como las llamas y el Cancerbero. Otras, son modernas, como las cenizas de Hiroshima. El poema persigue la batalla de quien lo escribe con sus sensaciones de impureza, sobre las que emerge, al final, con una «ascensión al Paraíso». Las metáforas de la purificación son celestiales: quien escribe asciende, se convierte en una Virgen acompañada de querubines. El poema sugiere que, para alcanzar dicho estado, es preciso destruir el ser anterior mediante el sufrimiento. Así como la mención de Hiroshima sugiere que la culpa podría ser colectiva y compartida por una sociedad, el debate individual de la purificación alude a una recuperación solitaria y no a los rituales comunitarios de penitencia. La poeta se distingue de sus amantes, rechazándolos en su ascenso al Paraíso. El poema es una pesadilla causada por la fiebre, conjurada a medias por las imágenes, a medias por el sonido.

\section{El proceso de traducción de Erich Fried}

Catherine Fried-Boswell, última esposa del autor, nos ofrece un retrato del traductor mientras trabaja en una obra de Shakespeare, posiblemente Enrique V:

La velocidad con la que traducía también me maravillaba. Vertía el texto al alemán a tal ritmo que lo dictaba directamente en el dictáfono para su secretaria de entonces, Grete Hornung. [...]. Yo intentaba imaginarme cómo se abría paso el pensamiento de Erich a través del original, buscando traducciones alternativas, descartándolas y componiendo sus piezas (Kaukoreit y Vahl 1991: 24).

Y, al. loc., la misma Fried-Boswell comenta sobre la forma de trabajar de su esposo:

Cuando la traducción estaba lista, la revisaba deprisa, la enviaba al impresor, donde se preparaba para el teatro y, luego, tras el final de la producción teatral - pues, durante los ensayos, podían añadirse otras modificaciones-, el texto se corregía de nuevo para su publicación. Por supuesto, yo sabía que eso era posible gracias a su extraordinaria capacidad de concentración. Y él me aclaró que trabajar así de rápido le permitía conservar de la mejor forma el tono, la temática de las imágenes y la estructura básica de la obra (Fried 2008: 71-74).

Fried (en entrevista con Wolfgang Görtschacher) confirma, asimismo, el método descrito por su esposa, que para él tenía la ventaja de permitirle no perder fácilmente la visión de conjunto del texto: «Traduzco lo más rápido posible, intento incluso recitarlo al dictáfono. Si no consigo encontrar una solución, subrayo una palabra para ser consciente del contexto. Después, corrijo despacio y a conciencia» (Görtschacher 1991: 132). 
Era un método que usaba en su propia obra (condensar el trabajo al principio para dedicar el máximo tiempo posible a la revisión), en la que consideraba cualquier versión siempre la penúltima. Tendente a la provisionalidad y al perfeccionismo, corregía y recorregía sus textos, y es notorio el caso de sus Gegengedichte (Befreiung von der Flucht: Gedichte und Gegengedichte), surgidos a la hora de reeditar, en 1968, sus Gedichte de 1958.

En el caso de la traducción, después de su trabajo «en borrador», corregía los diversos textos mecanografiados, añadía las sugerencias y deseos del director de la obra, del dramaturgista o de los actores en el caso del teatro, corregía las galeradas e, incluso, más tarde, las ediciones terminadas de las traducciones, en cuyas reediciones incluía también cambios. Preguntado por Görtschacher (1991: 139) sobre lo que cambia una y otra vez en sus traducciones, Fried aclara que solo detalles.

Nada hace suponer que este no fuese su método de trabajo habitual, como nos permitirá comprobar el estudio de los borradores y las diferentes versiones de «Tulips» $\mathrm{y}$ «Fever $103^{\circ} »$.

\section{La traducción de Ariel}

Según la carta de la editorial que se conserva en el archivo del autor, la publicación de Ariel en alemán se está planificando ya el 5 de abril de 1974. En dicha carta, la editora Karin Kiwus, de Bibliothek Suhrkamp, tranquiliza al traductor sobre sus temores en cuanto a la traducción de «Daddy» asegurándole que la edición será bilingüe y contará con sus notas del traductor sobre «Ariel» $\mathrm{y}$ «Nick and the Candlestick», a las que se puede añadir una sobre el poema mencionado. A ellas se añadirá en la edición final una nota sobre «Medusa» y la indicación de que los poemas se tradujeron entre 1965, año de publicación de Ariel, y 1974, año de publicación de su traducción (el último poema traducido en añadirse fue, según la carta de la editora, «The Bee Meeting»).

Esta indicación coincide con el recuerdo de Fried en entrevista con Wolfgang Görtschacher, en agosto de 1987:

Estaba contra la antología [se refiere a Ausgewählte Gedichte de Dylan Thomas), porque no podía responder realmente de esos poemas. Lo mismo me pasó más tarde con las traducciones de Sylvia Plath. Llevaba casi diez años rogándole a Unseld [Siegfried Unseld, de Suhrkamp Verlag, con quien Fried tenía relación como traductor desde 1959] que publicase poemas de Sylvia Plath. Cuando decidió que quería Ariel, tenía que ser a toda prisa. Protesté. Cuando dijo que, si no, no lo haría, pues lo hice; y no traduje lo bastante bien en absoluto (Seeber 2001: 41).

En la página de las notas también se agradece a Carla Wartenberg² su ayuda en la traducción.

\subsection{Cronología de las versiones}

En el mencionado archivo de la Biblioteca Nacional de Viena, donde se guarda todo el legado del autor en cuanto a producción literaria se refiere, se conservan cuatro versiones de Ariel con sus correspondientes correcciones. De ellas, tres son previas a la publicación, a las que se añade el texto publicado por Suhrkamp Verlag, que el traductor ha corregido en el caso de «Tulpen». La grafía de las correcciones sugiere que son casi en su totalidad del propio Erich Fried. De hecho, ha sido imposible determinar la naturaleza de la ayuda de Carla Wartenberg partiendo de las correcciones de los borradores, aunque la existencia de dos copias de la traducción entregada a la editorial sugiere que pudo ser este el paso en el que se produjo la colaboración.

$\mathrm{Si}$ bien las versiones iniciales parecen muy distintas, las alusiones al original y al orden en que los poemas aparecen en este sugieren que la versión con más correcciones es la primera. En esta aparece apenas un número como identificación de la página del original de la que procede la traducción ( 20 en el caso de «Tulips» y 58 en el caso de «Fever $\left.103^{\circ} »\right)$. En la tercera versión previa a la publicación (que coincide en gran medida con la considerada segunda versión), hay cifras correlativas hechas con un sello que marcan el orden correspondiente a los poemas en el volumen final (en este caso, los números que corresponden a las dos páginas de «Tulips» son 00016 y 00017 y los que corresponden a «Fever $103^{\circ} », 00069$ y 00070). Los poemas aparecerán, finalmente, en el sexto y el vigésimo cuarto lugar, que corresponden a las páginas 26 a 33 y 114 a 119 del volumen publicado (que sigue la edición británica de Ariel, cuyo orden estableció Ted Hughes).

(2) Traductora, huida de Berlín a Londres y residente en Hampstead. Casada entre 1985 y 2014 con el neurólogo Paul Fatt. 
La versión publicada es muy parecida a esta tercera versión, que consideramos que ha de ser la entregada a la editorial.

No era en absoluto extraño que Fried hiciese correcciones sobre sus obras publicadas. En la mayor parte de los casos, como se ha mencionado ya, lo que cambia son detalles mínimos. Lo que choca de Ariel es que, en el ejemplar del traductor, solo hay cambios en la traducción de «Tulips» y estos son muchos, casi como para poder considerar la versión corregida una quinta versión.

El método de trabajo en el caso de la traducción de Ariel parece corresponderse, en gran medida, con el expuesto más arriba. El borrador de la traducción de Fried se elabora directamente a máquina, corrigiendo pequeños detalles a medida que se escribe. Sobre esa versión mecanografiada, el traductor corrige con tinta negra y, más tarde, con tinta azul en el caso de «Tulpen» y en lápiz, tinta negra y tinta azul en el caso de «39,5 Fieber».

Los cambios son de orden de palabras y ortotipográficos (muchos puntos finales añadidos a los versos), de sonoridad («laufen» se sustituye por «tolln» [para traducir «roll»]) y de precisión léxica («schmerzhaft» pasa a ser «fiebrig» [para traducir: «aguey»]).

En la versión limpia, mecanografiada de nuevo, se corrige con tinta negra de bolígrafo y rotulador en el caso de «Tulpen», y con tinta negra y roja en el caso de «39, $5^{\circ}$ Fieber». Las correcciones en rojo, todas de carácter ortotipográfico, parecen de otra mano, que seguramente se corresponde, como se ha mencionado más arriba, con la de Carla Wartenberg.

\subsection{La recepción de Ariel en alemán}

Quizá la mejor mala crítica a la traducción de Ariel al alemán sea la de Werner Vordtriede, él mismo traductor, antes de entrar a listar, muy al uso, una serie de errores de sentido (que ascienden a cinco) y a lamentar la falta de un prólogo a la obra:

La traducción de Erich Fried intenta, también en este caso, ser muy literal y, con ello, salvar parte de la técnica sonora y los juegos de palabras con destreza. Es un arte honrado, una discreta ayuda de lectura y, a menudo, convincente en su carácter. Pero, cuando la literalidad se convierte en perífrasis aclaradora a la manera de un diccionario, el ritmo, el ingenio y la elegancia concisa se pierden ligeramente, como sucede con los monosílabos [sobre los intentos de suicidio de la autora] (Vordtriede 1974).

También Rudolf Hartung opina, en el Süddeutsche Zeitung, que Fried ha solucionado la tarea de traducción, casi irresoluble, de manera respetable, aunque hace constar:

[Q]ue su fallo consiste en una excesiva fidelidad literal cuyo efecto supone una infidelidad al original. Pues las traducciones de este tipo son consecuencia de la infundada creencia de que hay cierta armonía preestablecida entre dos lenguas: como si existiese la garantía de que una traducción muy cercana al original inglés hubiese de arrojar como resultado también un poema en alemán (Hartung 1975).

Heimann (1987: 191-192) comenta, asimismo, que la pérdida real para el lector de la traducción está en que el alemán de Ariel debilita en gran medida el ritmo (de los monosílabos que aceleran entre los polisílabos que frenan) y la musicalidad (entendida como dramatismo) del original. El original sigue el ritmo de la respiración, mientras que el esfuerzo de la traducción lo hace artificial y no responde al ritmo del habla cotidiana. Asimismo, incide en que, lexicalmente, algunos poemas resultan «aplanados» y no tienen la agresividad verbal del original (un efecto secundario también del cambio de ritmo), y en que la red de coherencias temáticas que permite la repetición de motivos o palabras no es tan estrecha en la traducción, lo que resta al lector alemán la sensación de encontrarse ante una antología de poemas que han surgido juntos.

Añade que el problema de los géneros en alemán reviste cierta importancia en cuanto a la imaginería de los poemas escritos por una autora. Y que la exactitud semántica que busca el traductor se convierte en una traba para la traducción, que sacrifica la pasión, el dramatismo y la magia, así como la fuerza y el dinamismo del original. 
Parece, pues, evidente que la base de todas las críticas es que Fried escribe en un idioma distinto al original, lo que no deja de ser, como afirma Eduardo Mendoza, el principal problema de las traducciones.

No me permitiré opinar sobre la calidad de la traducción de un poemario en un idioma en el que no soy nativa. Pero, tras estudiar cuidadosamente el análisis de las traducciones llevado a cabo por Vordtriede y Heimann, sí puedo, como traductora, afirmar que los errores que se señalan necesitan en gran medida de la comparación con el original, cosa que facilita la versión bilingüe. No obstante, si se hubiese de leer el poemario en su versión alemana exclusivamente, las imágenes, la fuerza del lenguaje de Sylvia Plath y su carácter poético quedarían excelentemente reflejados en la traducción de Erich Fried, y creo que esa es la sensación que los críticos, en definitiva, también transmiten.

\subsection{Comparación de versiones}

\subsection{1. «Tulpen»}

El inglés de los poemas de Sylvia Plath en Ariel es sencillo y coloquial, referido a realidades cotidianas que solo adquieren poder como imagen (p. ej., pastillero, cantos, juego de té, cómodas, libros, almohada, embozo y, en realidad, todo el vocabulario en torno a la cama).

La estructura métrica es libre y natural, y responde en gran medida a la cadencia del habla. La propia Plath había comentado, en cuanto al ritmo de estos textos, que se trataba de "poems for the ear, not the eye, [...], poems written out loud ${ }^{3}$ » (Rosenthal 1970: 75); poemas, pues, cuyo componente acústico (repeticiones de palabras y vocálicas o, raramente, consonánticas, y cierto efecto de staccato creado por la acumulación de monosílabos, aliteraciones y asonancias) resulta de gran importancia.

Existen varios campos léxicos en el poema: el invierno, los colores (el blanco de la nieve, las paredes, las cofias de las enfermeras; el verde de las camillas; el negro del fin de semana, de las fotos; el rojo de los tulipanes, la herida abierta), la cama (almohadas, embozos, la postración), que crean imágenes también en torno a la repetición, incluida la del movimiento y la falta de él (la postración de la voz que habla en el poema frente a las idas y venidas de las enfermeras y, en un extremo de sensibilidad, la apertura de los tulipanes).

La primera versión de Erich Fried recoge en gran medida estas características. El alemán es sencillo y se conservan las repeticiones. Ciertamente, no cuenta siempre con el efecto staccato mencionado; donde Plath escribe: «Like an eye between two white lids that will not shut», su traducción: «Wie ein Auge zwischen zwei weißen Lidern die nicht zufallen wollen» no respeta, desde luego, la profusión de monosílabos, aunque se ha de reconocer que tiene cierto sonido difícil que reproduce la intención sonora del original. Esto mismo sucede en otros versos, donde las sucesiones de monosílabos se convierten en series de bisílabos con tónicas y átonas alternadas, con un efecto similar. Incluso en el caso de los movimientos de las enfermeras, que en inglés repiten varias veces «pass» reproduce las repeticiones mediante «vorbei».

Los campos léxicos también se conservan. Y, frente a la imposibilidad del alemán de usar el adjetivo de color «rot» (rojo) invariablemente («Die Tulpen sind erstens zu rot» $\mathrm{y}$ «rote Bleilote»), recupera la repetición usando «Rot» como sustantivo para «redness».

¿Cuáles son, pues, las correcciones que hace a esta versión?

Más allá de los puros cambios ortotipográficos (mayúsculas de sustantivos que se han omitido en la primera versión, erratas o comas que aparecen o desaparecen), hay por una parte algún cambio que incide en la repetición de sonidos y palabras. Se propone, por ejemplo: «Nun wirbelt und kräuselt die Luft sich rund um wie ein Fluß / Sich wirbelt und kräuselt eine gesunkene rostigrote Maschine», para traducir: «Now the air snags and eddies round them the way a river / Snags and eddies round a sunken rust-red engine», donde en la primera versión se había usado: «Nun schlägt die Luft Wellen um sie und stößt an sie wie ein Fluß / Wellen schlägt und sich kräuselt um eine gesunkene rostigrote Maschine» (en la siguiente revisión, se corrige la ausencia de la repetición correspondiente a «round»: «Nun wirbelt und kräuselt die Luft sich um sie wie ein Fluß / Sich wirbelt und kräuselt um eine versunkene rostigrote Maschine»).

Varios cambios suponen el acortamiento de las palabras y el cambio de ritmo de las sílabas tónicas. Así, por ejemplo, «ruhig alleine liegen» pasa a ser «Alleinliegen ruhig»; «Sie ziehen meine Aufmerksamkeit auf sich, die glücklich war» se convierte en «Sie sammeln meine Aufmerksamkeit, die froh war»; o «Tagesgewänder» se

(3) Poemas para el oído, no la vista, [...], poemas escritos en voz alta. 
corrige a «Tageskleider».

No faltan las correcciones de precisión léxica. Aunque podría no parecerlo, la corrección de «ein dreißig Jahre alter Lastkahn» a «einen dreißigjährigen Lastkahn» facilita dicha precisión, aunque quizá la más evidente de estas correcciones sea la de «Rollwagen» por «Fahrbett».

Las correcciones en la segunda versión son mínimas y, aunque las hay ortotipográficas y de reducción de sílabas («andre» por «andere» o «ganz» por «völlig»), la mayoría sí se centran en este caso en las imágenes (p. ej., «nur den Namensschild, und ein Stück, zwei kleine Schmuckstücke» pasa, restando sílabas también, a «nur den Namen an Arm und ein wenig Kleinkram», que mantiene mejor el ritmo y el sentido del original «a name tag, a few trinkets»; o «aus Papier ausgeschnittten» pasa a «ein papierener Scherenschnittschatten», que refleja mucho mejor la imagen de «cut-paper shadow»).

Esta segunda versión apenas cambiará hasta su publicación. En cuanto a las correcciones que propone para esta, lo más sorprendente será, sin duda, que en no pocas ocasiones vuelve a las propuestas originales de la que se ha considerado primera versión.

\subsection{2. «39, $5^{\circ}$ Fieber»}

El primer cambio evidente en la traducción de este poema es la conversión a grados Celsius de la temperatura febril, cosa lógica si no se quiere refrenar la fuerza de la imagen.

Este poema de naturaleza trascendental gira, como se ha adelantado ya en el apartado 2.1. en torno a la pureza ( «pure», en alemán «rein»), que aparece en forma de adjetivo varias veces en el texto y que se connota de distinta forma que «clean» en la segunda estrofa. Esta diferencia se pierde en la traducción al alemán, que usa también «rein» («rein zulecken», o «reinzulecken» en la versión corregida y publicada).

Lo que más llama la atención de este poema es la repetición de términos, como si las mismas palabras horadaran una y otra vez la conciencia febril de quien habla. Son asimismo características las repeticiones de sonidos (la i corta - sin/sin/tinder/indeleble - y la s — sin/sin/cries/smell — de la tercera estrofa o la combinación de i larga y corta y sh — greasing/bodies/Hiroshima/eating/sin, así como Hiroshima/ash — en la novena).

Fried se esfuerza por obtener una atmósfera sonora similar en la traducción alemana. Mantiene las rimas finales, internas y asonantes, busca palabras onomatopéyicas y repite palabras aisladas o sintagmas, refleja en alemán la intensidad febril del habla.

Véase, p. ej., «Die fetten Leiber von Ehebrechern ein / Wie Hiroschima-Asche und freuen sich ein. / Die Sünde. Die Sünde. Runde», que corregirá para la publicación a: «Sie fettet die Leiber der Ehebrecher ein. / Wie Hiroshima-Asche und frißt sich in Haut und Rinde. / Die Sünde. Die Sünde». O también la mortificante visión de la asfixia lenta de Isadora Duncan, que se transmite en alemán con una traducción en la que Fried intenta reproducir el sonido ahogado de quien habla: «Ein Ende wird sich verfangen und sich im im [sic] Rad verankern. / So gelbe schwere Schwaden / Machen ihr eigenes Element. Die steigen nicht auf», que acabará por ser «Ein Ende wird sich verfangen und ankern im Rad. /So gelbe schwere Schwaden / Machen ihr eigenes Element. Sie steigen nicht auf», aumentando ligeramente el efecto sonoro con mínimas correcciones.

Las estrofas 14 y 15 («Does not my heat... I, love, I») se leen como la descripción de un orgasmo, si bien carente de sexualidad, pues renuncia al hombre que habla y a todos los demás. Pero la 15 suena también casi como uno, algo que consigue la sucesión de monosílabos. Esto no se recoge en absoluto en la primera versión de la traducción que, sorprendentemente, en este caso se mantiene casi invariada hasta la publicación. Sin embargo, el traductor parece consciente de que, si bien ha conseguido la descripción, no tiene la imagen sonora y, a juzgar por las correcciones, busca compensarla en la traducción de la siguiente estrofa (16: «Am a pure acetylene / Virgin / Attended by roses,»), en la que va abreviando y buscando la alteración de sílabas tónicas y átonas en busca del efecto staccato («Heben sich, und ich, Liebster, ich / Bin eine reine Acetylen- / Jungfrau, umhegt von Rosen», que pasará a «Fliegen, -und ich, Liebster, ich / Bin eine reine Acetylen- / jungfrau, von Rosen geleitet»).

Si bien se ha criticado también que la renuncia a los hombres aparece difuminada en la traducción por culpa del dativo: «Not you, nor him / Not him, nor him» se traduce como «Nicht dir, noch ihm / Nicht ihm, noch ihm», que se publicará al final sin las comas intermedias, parece que ni el ritmo ni el caso renieguen del original, aunque sí se ha de reconocer que puede perder cierto dramatismo («not you» es más directo porque es una 
negación del lector masculino).

Por lo demás, las imágenes se conservan con todo su colorido y las correcciones, casi todas las cuales se producen en el paso de la primera a la segunda versión (donde no deja de sorprender que muchas veces se recurra, tras corregir, a la alternativa del borrador) se dirigen en su mayoría a aumentar el efecto sonoro cortante y jadeante (aumentan los monosílabos, los sonidos oclusivos y fricativos), todo lo cual se puede comprobar en los anexos a este artículo, donde se han recogido todas las correcciones de las diversas versiones de ambos poemas.

\section{Conclusiones}

Como «agente literario», Fried demostró una vez más con la traducción de los poemas de Plath su intuición para la poesía y su capacidad como traductor. Pese a las críticas a su traducción - centradas, a veces, en algo tan indudable como dato y poco comprobable como influencia como que era un hombre traduciendo a una mujer-, su traducción reproduce en abundante medida la lírica y las imágenes del original. Es cierto que no se puede juzgar toda la obra por lo ofrecido en este artículo, pero consideramos que resulta paradigmático de lo logrado en toda la antología. Pese a las carencias que puede mostrar, se palpa la búsqueda de soluciones que reproduzcan el ritmo de los poemas, al que se da la importancia debida, y esto desde el primer borrador y a través de sus modificaciones.

Arriesgando una opinión personal, entendemos que la forma en que Fried se siente identificado con los poemas (recordemos su insistencia en la necesidad de traducirlos al alemán) y trabaja en imágenes que exceden su género y su inclinación (cis heterosexual, si hemos de definirlo en términos actuales) no hace sino abundar en la universalidad de la poesía de Plath. Indudablemente, la poeta parte de su experiencia femenina, pero los miedos y el sentimiento de culpa son algo que todo el mundo puede entender, y no en menor medida un superviviente de la persecución nazi que toda su vida estaría entregado a la lucha por la justicia.

El estudio de los borradores de la traducción de Ariel permite, asimismo, confirmar el método de trabajo declarado por Fried y descrito por su esposa, y también la intuición de Fried para el idioma. Parece evidente que el hecho de dictar sus traducciones, de leerlas en voz alta, le da la ventaja indudable de poder trabajar sobre el sonido con tanta claridad e intención como sobre el contenido metafórico de los poemas.

La introducción de las metáforas, de la iconografía de Plath en alemán, se produce así en la búsqueda de un léxico cotidiano pero preciso, de un ritmo que reproduce el habla en otro idioma intentando conservar el elemento extraño del yambo tan común en inglés. Si bien esta fidelidad semántica es lo que se critica con más inquina en la traducción de Fried (muy en la línea de la recreación descrita por Schleiermacher [1813] en su ensayo sobre los principios de la traducción, que no deja de ser una base de las ideas en sentido contrario que más tarde expondrá Erich Fried en torno a su modo de traducir en las pocas ocasiones en que habló de ello), no deja de ser uno de los mayores logros de su traducción: no deber renunciar a ella en busca del ritmo y, con ello, introducir la imaginería plathiana en el marco alemán. En cuanto a la influencia de esta traducción en la obra de Fried, no parece exceder la que la traducción de literatura inglesa tuvo en su poesía, de la que se llegó a reprochar que era «lírica inglesa escrita en alemán».

Es evidente también que el hecho de prestar atención al proceso traslativo de Fried, más allá de que su traducción de poesía se pueda englobar en la definición clásica de traducción, nos acerca al concepto de postraducción (Gentzler 2017), al considerar al traductor como agente de reenmarcación cultural. Y me parece necesario señalar, en este sentido, la importancia que para el estudio de las decisiones del traductor tiene el hecho de que Erich Fried no trabajase con un ordenador, sino con versiones a máquina y corregidas con tinta o lápiz. Temo que con la digitalización del oficio se pierda valiosa información sobre el proceso de traducción, que podría ayudar a los investigadores del futuro interesados en el tema. 
Bibliografía:

Fried, C. (2008). Über kurz oder lang. Wagenbach.

Fried, E. (1981). Kinder und Narren. Erzählungen. Wagenbach.

Fried, E. (1988). Es erinnert sich Erich Fried. En "Hier ist England" - "Live aus London": Das deutsche Programm der British Broadcasting Corporation, 1938-1988 (pp. 148-149). BBC External Services.

Fried, E. (1991). Übersetzen oder Nachdichten? En V. Kaukoreit y H. Vahl (Eds.), Einer singt aus der Zeit gegen die Zeit. Erich Fried 1921-1988. Materialien und Texte zu Leben und Werk (pp. 79-93). Häuser.

Fried, E., versiones de traducción del Nachlass Erich Fried, ÖLA 4/90, Gruppe 1.8.4, Einzelübersetzungen Weitere Autoren, consultadas por la autora en el Archivo Erich Fried de la Biblioteca Nacional de Austria, dirigido por el Dr. Volker Kaukoreit, en junio de 2020.

Gentzler, E. (2017). Translation and Rewriting in the Age of Post-Translation Studies. Routledge. https://doi org/10.4324/9781315619194

Görtschacher, W. (1991). Nur die Schattseite des Dichters! Erich Fried als Übersetzer von Dylan Thomas. En W. Pöckl (Ed.),
Österreichische Dichter als Übersetzer (pp. 123-186). Österreichische Akademie der Wissenschaften. Veröffentlichungen der Kommission für Literaturwissenschaft $\mathrm{Nr}$. 12

Hartung, R. (8-9 de febrero de 1975) Selbstmörderisch eins mit dem Ritt. Süddeutsche Zeitung (32).

Heimann, A. (1987). "Bless Thee! Thou art Translated". Erich Fried als Übersetzer moderner englischsprachiger Lyrik Münchner Studien zur neueren englischen Literatur, vol. 4

Hughes, T. (1970). Notes on the Chronological Order of Sylvia Plath's Poems. En C. Newman (Ed.), The Art of Sylvia Plath (pp. 187-199). Indiana University Press.

Kaukoreit, V. y Vahl, H. (Eds.) (1991). Einer singt aus der Zeit gegen die Zeit. Erich Fried 1921-1988. Materialien und Texte zu Leben und Werk. Häuser.

McClanahan, T. (1980). Sylvia Plath. En D J. Greine (Ed.), Dictionary of Literary Biography, vol. 5: American Poets Since World War II. Gale Research.

Oates, J. C. (5 de noviembre de 2000). Raising Lady Lazarus, a review of The Unabridged Journals of Sylvia Plath, 1950-1962. The
New York Times Book Review. http:// movies2.nytimes.com/books/00/11/05/ reviews/001105.05oatest.htm

Plath, S. (2016 [1974]). Ariel. Suhrkamp.

Rosenthal, M. L. (1970). Sylvia Plath and Confessional Poetry. En C. Newman (Ed.), The Art of Sylvia Plath (pp. 69-76). Indiana University Press.

Rothschild, T. (1986). Die Lyrik ist keineswegs am Ende. Ein Gespräch mit dem Dichter Erich Fried (1975). En R. Wolff (Ed.), Gespräche und Kritiken (pp. 17-21). Bouvier.

Schleiermacher, F. (1813). Über die verschiedenen Methoden des Übersetzens. En D. Ernst (Ed.), Memoires de l'academie royale des sciences et belles lettres. 1812/13 (pp. 143-172).

Seeber, U. (2001). "All right, what's left": historische und aktuelle kritische Positionen im Andenken an Erich Fried: Texte zum Erich Fried Symposium 2001. Dokumentationsstelle für Neuere Österreichische Literatur im Literaturhaus Sondernr. 58.

Vordtriede, W. (25 de octubre de 1974). Der Weg des Todes. Die Zeit (44). https://www. zeit.de/1974/44/der-weg-des-todes 
Anexo I

ARIEL - TULIPS - TULPEN

\begin{tabular}{|c|c|c|}
\hline ORIGINAL & 1. ${ }^{a}$ VERSIÓN & CORRECCIONES \\
\hline The tulips are too excitable, it is winter here. & Die Tulpen sind zu erregbar, es ist Winter hier. & Die Tulpen sind zu erregbar, es ist hier Winter. \\
\hline $\begin{array}{l}\text { Look how white everything is, how quiet, how } \\
\text { snowed-in. }\end{array}$ & Sieh, wie weiß alles ist, wie still, wie eingeschneit. & Sieh, wie weiß alles ist, wie still, wie eingeschneit. \\
\hline I am learning peacefulness, lying by myself quietly & Ich lerne friedlichkeit, ruhig alleine liegen & Ich lerne Friedlichkeit, Alleinliegen, ruhig \\
\hline $\begin{array}{l}\text { As the light lies on these white walls, this bed, } \\
\text { these hands. }\end{array}$ & $\begin{array}{l}\text { Wie das Licht liegt auf diesen weißen Wänden, diesem Bett, } \\
\text { diesen Händen }\end{array}$ & $\begin{array}{l}\text { Wie das Licht liegt auf diesen weißen Wänden, diesem Bett, } \\
\text { diesen Händen. }\end{array}$ \\
\hline I am nobody; I have nothing to do with explosions. & $\begin{array}{l}\text { Ich bin niemand; ich habe nichts zu schaffen mit } \\
\text { Explosionen }\end{array}$ & Ich bin niemand; ich habe nichts zu schaffen mit Explosionen. \\
\hline $\begin{array}{l}\text { I have given my name and my day-clothes up to } \\
\text { the nurses }\end{array}$ & $\begin{array}{l}\text { Ich hol meinen Namen und meine Tagesgewänder den } \\
\text { Schwestern gegeben }\end{array}$ & $\begin{array}{l}\text { Ich habe meinen Namen und meine Tageskleider den } \\
\text { Schwestern gegeben, }\end{array}$ \\
\hline $\begin{array}{l}\text { And my history to the anesthetist and my body to } \\
\text { surgeons. }\end{array}$ & $\begin{array}{l}\text { und meine Geschichte dem Anästhesisten und meinen Leib } \\
\text { den Chirurgen. }\end{array}$ & $\begin{array}{l}\text { Meine Geschichte dem Anästhesisten und meinen Leib den } \\
\text { Chirurgen. }\end{array}$ \\
\hline $\begin{array}{l}\text { They have propped my head between the pillow } \\
\text { and the sheet-cuff }\end{array}$ & $\begin{array}{l}\text { Sie haben meinen Kopf aufgestellt zwischen Kissen und } \\
\text { Überschlaglaken }\end{array}$ & $\begin{array}{l}\text { Sie haben meinen Kopf aufgestellt zwischen Kissen und } \\
\text { Überschlaglaken }\end{array}$ \\
\hline $\begin{array}{l}\text { Like an eye between two white lids that will not } \\
\text { shut. }\end{array}$ & $\begin{array}{l}\text { Wie ein Auge zwischen zwei weißen Lidern die nicht zufallen } \\
\text { wollen. }\end{array}$ & $\begin{array}{l}\text { Wie ein Auge zwischen zwei weißen Lidern, die nicht zufallen } \\
\text { wollen. }\end{array}$ \\
\hline Stupid pupil, it has to take everything in. & Dummer Schüler, es muß alles in sich aufnehmen. & Dummer Schüler, es muß alles in sich aufnehmen. \\
\hline The nurses pass and pass, they are no trouble, & Die Schwestern gehen vorbei und vorbei, die stören nicht, & Die Schwestern gehen vorbei und vorbei, die stören nicht, \\
\hline $\begin{array}{l}\text { They pass the way gulls pass inland in their white } \\
\text { caps, }\end{array}$ & $\begin{array}{l}\text { Sieh gehen vorbei wie Möven ins Landesinnere in ihren } \\
\text { weißen Hauben, }\end{array}$ & $\begin{array}{l}\text { Sie gehen vorbei wie Möwen [llegible tachado] landen in ihren } \\
\text { weißen Hauben, }\end{array}$ \\
\hline $\begin{array}{l}\text { Doing things with their hands, one just the same } \\
\text { as another, }\end{array}$ & Tun etwas mit ihren Händen, jede genau wie die andere, & Tun etwas mit ihren Händen, jede genau wie die andere, \\
\hline So it is impossible to tell how many there are. & So daß es unmöglich ist zu sagen, wieviele es sind. & So daß es unmöglich ist zu sagen, wieviele es sind. \\
\hline My body is a pebble to them, they tend it as water & $\begin{array}{l}\text { Mein Körper ist ein Kiesel für sie, sie pflegen ihn so wie } \\
\text { Wasser }\end{array}$ & Mein Leib ist ein Kiesel für sie, sie pflegen ihn so, wie Wasser \\
\hline $\begin{array}{l}\text { Tends to the pebbles it must run over, smoothing } \\
\text { them gently. }\end{array}$ & Kiesel pflegt über die es fließen muß und sie sanft glättet. & Kiesel pflegt, über die es fließen muß, und sie sanft glättet. \\
\hline $\begin{array}{l}\text { They bring me numbness in their bright needles, } \\
\text { they bring me sleep. }\end{array}$ & $\begin{array}{l}\text { Sie bringen mir Stumptheit in ihren blanken Nadeln, sie } \\
\text { bringen mir Schla }\end{array}$ & $\begin{array}{l}\text { Sie bringen mir Stumpfheit in ihren blanken Nadeln, sie bringen } \\
\text { mir Schlaf. }\end{array}$ \\
\hline
\end{tabular}




\begin{tabular}{|c|c|c|}
\hline ORIGINAL & 1. ${ }^{a}$ VERSIÓN & CORRECCIONES \\
\hline Now I have lost myself I am sick of baggage-- & $\begin{array}{l}\text { Nun da ich mich selbst verloren habe, macht mich jedes } \\
\text { Gepäck krank - }\end{array}$ & $\begin{array}{l}\text { Nun hab ich mich selbst verloren, jedes Gepäck macht mich } \\
\text { krank - }\end{array}$ \\
\hline $\begin{array}{l}\text { My patent leather overnight case like a black } \\
\text { pillbox, }\end{array}$ & Mein Kleiner Lackkoffer wie eine schwarze Pillenschachtel, & Mein kleiner Lackkoffer wie eine schwarze Pillenschachtel, \\
\hline $\begin{array}{l}\text { My husband and child smiling out of the family } \\
\text { photo; }\end{array}$ & $\begin{array}{l}\text { Mein Mann und mein Kind, die lächeln aus dem } \\
\text { Familienfoto; }\end{array}$ & Mein Mann und mein Kind, die lächeln aus dem Familienfoto; \\
\hline $\begin{array}{l}\text { Their smiles catch onto my skin, little smiling } \\
\text { hooks. }\end{array}$ & $\begin{array}{l}\text { Ihr Lächeln verfängt sich in meine Haut, wie lächelnde } \\
\text { Haken. }\end{array}$ & Ihr Lächeln verfängt sich in meine Haut wie lächelnde Haken. \\
\hline I have let things slip, a thirty-year-old cargo boat & Ich hab alles treiben lassen ein dreiBig Jahre alter Lastkahn, & Ich hab alles treiben lassen, einen dreißigijährigen Lastkahn, \\
\hline stubbornly hanging on to my name and address. & $\begin{array}{l}\text { Hartnäckig halte ich fest an meinem Namen und meiner } \\
\text { Adresse. }\end{array}$ & $\begin{array}{l}\text { Hartnäckig halte ich fest an meinem Namen und meiner } \\
\text { Adresse. }\end{array}$ \\
\hline $\begin{array}{l}\text { They have swabbed me clear of my loving } \\
\text { associations. }\end{array}$ & $\begin{array}{l}\text { Sie haben mich reingetupft von all meinen Liebenden (es) } \\
\text { Verbindungen. }\end{array}$ & Sie haben mich reingetupft von allen Bindungen meiner Liebe. \\
\hline $\begin{array}{l}\text { Scared and bare on the green plastic-pillowed } \\
\text { trolley }\end{array}$ & $\begin{array}{l}\text { Verängstigt und nackt auf dem grünen Fahrbett mit grünem } \\
\text { Plastikkissen. }\end{array}$ & $\begin{array}{l}\text { Verängstigt und nackt auf dem grünen Rollwagen mit } \\
\text { Plastikkissen. }\end{array}$ \\
\hline $\begin{array}{l}\text { I watched my teaset, my bureaus of linen, my } \\
\text { books }\end{array}$ & $\begin{array}{l}\text { Ich sah mein Teeservice meinen Wäscheschrank, meine } \\
\text { Bücher, }\end{array}$ & $\begin{array}{l}\text { Ich sah mein Teeservice meinen Wäscheschrank, meine } \\
\text { Bücher }\end{array}$ \\
\hline $\begin{array}{l}\text { Sink out of sight, and the water went over my } \\
\text { head. }\end{array}$ & $\begin{array}{l}\text { die sinken, außer sich, und das Wasser stieg mir über den } \\
\text { Kopf. }\end{array}$ & Außer Sicht sinken, und das Wasser stieg mir über den Kopf. \\
\hline I am a nun now, I have never been so pure. & Ich bin eine Nonne jetzt, nie noch war ich so rein. & Ich bin eine Nonne jetzt, nie noch war ich so rein. \\
\hline I didn't want any flowers, I only wanted & Ich wollte keine Blumen, ich wollte nur & Ich wollte keine Blumen, ich wollte nur \\
\hline $\begin{array}{l}\text { To lie with my hands turned up and be utterly } \\
\text { empty. }\end{array}$ & So liegen, Handflachen nach oben, und völlig leer sein. & So liegen, Handteller [aufwärts] nach oben, und völlig leer sein \\
\hline How free it is, you have no idea how free-- & Wie frei das ist. Ihr habe keine Ahnung wie frei - & Wie frei das ist. Ihr habt keine Ahnung, wie frei - \\
\hline The peacefulness is so big it dazes you, & Die Friedlichkeit ist so groß, daß sie einen betäubt. & Die Friede ist so groß, daß er einen betäubt. \\
\hline And it asks nothing, a name tag, a few trinkets. & $\begin{array}{l}\text { Und sie verlangt nichts, nur ein Namensschild, ein, zwei } \\
\text { kleinigkeiten. }\end{array}$ & $\begin{array}{l}\text { Und er verlangt nichts, nur den Namensschild, und ein Stück, } \\
\text { zwei kleine Schmuckstücke. }\end{array}$ \\
\hline $\begin{array}{l}\text { It is what the dead close on, finally; I imagine } \\
\text { them }\end{array}$ & $\begin{array}{l}\text { Das ist es, womit sich die Toten abfinden schließlich; ich } \\
\text { sehe sie }\end{array}$ & Das ists, womit sich zuletzt die Toten abfinden; ich sehe sie \\
\hline $\begin{array}{l}\text { Shutting their mouths on it, like a Communion } \\
\text { tablet. }\end{array}$ & Ihre Münder schließen um es, wie am eine Oblate. & Ihre Münder umschließen um es wie eine Oblate. \\
\hline
\end{tabular}




\begin{tabular}{|c|c|c|}
\hline ORIGINAL & 1. a VERSIÓN & CORRECCIONES \\
\hline $\begin{array}{l}\text { The tulips are too red in the first place, they hurt } \\
\text { me. }\end{array}$ & Die Tulpen sind erstens zu rot, sie tun mir weh. & Die Tulpen sind erstens zu rot, sie tun mir weh. \\
\hline $\begin{array}{l}\text { Even through the gift paper I could hear them } \\
\text { breathe }\end{array}$ & $\begin{array}{l}\text { Sogar durch das Geschenkpapier konnte ich hören, wie sie } \\
\text { atmen. }\end{array}$ & $\begin{array}{l}\text { Sellost durch das Geschenkpapier konnte ich hören, wie sie } \\
\text { atmen. }\end{array}$ \\
\hline $\begin{array}{l}\text { Lightly, through their white swaddlings, like an } \\
\text { awful baby. }\end{array}$ & Leicht, durch die weißen Hüllen, wie ein entsetzliches Baby. & Leicht, durch die weißen Hüllen, wie ein furchtbares Baby. \\
\hline Their redness talks to my wound, it corresponds. & $\begin{array}{l}\text { Ihr Rot spricht zu meiner Wunde, es hängt zusammen mit } \\
\text { ihr. }\end{array}$ & Ihr Rot spricht zu meiner Wunde, es hängt zusammen mit ihr. \\
\hline $\begin{array}{l}\text { They are subtle : they seem to float, though they } \\
\text { weigh me down, }\end{array}$ & $\begin{array}{l}\text { Sie sind schlau: sie scheinen zu schweben, obwohl sie mich } \\
\text { niederwuchten }\end{array}$ & $\begin{array}{l}\text { Sie sind schlau: sie scheinen zu schweben, obwohl sie mich } \\
\text { niederwuchten, }\end{array}$ \\
\hline $\begin{array}{l}\text { Upsetting me with their sudden tongues and their } \\
\text { color, }\end{array}$ & $\begin{array}{l}\text { Mich aus der Ruhe bringen mit ihren plötzlichen Zungen und } \\
\text { ihrer Farbe }\end{array}$ & $\begin{array}{l}\text { Mich aus der Ruhe bringen mit ihren plötzlichen Zungen und } \\
\text { ihrer Farbe, }\end{array}$ \\
\hline A dozen red lead sinkers round my neck. & Ein Dutzend rote bleilote um meinen Hals. & Ein Dutzend rote Bleilote um meinen Hals. \\
\hline Nobody watched me before, now I am watched. & Niemand sah mich zuvor, nun bin ich beobachtet. & Zuvor sah mich niemand, nun bin ich beobachtet. \\
\hline The tulips turn to me, and the window behind me & Die Tulpen wenden sich mir und dem Fenster hinter mir zu & $\begin{array}{l}\text { Die Tulpen wenden sich mir zu und dem Fenstern in meinem } \\
\text { Rücken }\end{array}$ \\
\hline $\begin{array}{l}\text { Where once a day the light slowly widens and } \\
\text { slowly thins, }\end{array}$ & $\begin{array}{l}\text { Wo einmal am Tag das Licht langsam weiter wird und } \\
\text { langsam dünner (schwindet) }\end{array}$ & $\begin{array}{l}\text { Wo einmal am Tag das Licht langsam bloß wird und langsam } \\
\text { schwindet }\end{array}$ \\
\hline $\begin{array}{l}\text { And I see myself, flat, ridiculous, a cut-paper } \\
\text { shadow }\end{array}$ & $\begin{array}{l}\text { Und ich sehe mich lächerlich flach schnitten, ein Schatten, } \\
\text { aus Papier ausgesc//(Ein Scherenschnittschatten). }\end{array}$ & $\begin{array}{l}\text { Und ich sehe mich lächerlich flach, einen Schatten, aus Papier } \\
\text { ausgeschnitten. }\end{array}$ \\
\hline $\begin{array}{l}\text { Between the eye of the sun and the eyes of the } \\
\text { tulips, }\end{array}$ & Zwischen dem Auge der Sonne und den Auge der Tulpen, & Zwischen dem Auge der Sonne und den Augen der Tulpen, \\
\hline $\begin{array}{l}\text { And I have no face, I have wanted to efface } \\
\text { myself. }\end{array}$ & Und ich hab kein Gesicht, ich wollte mich ohne Gesicht. & Und ich habe kein Gesicht, ich wollte mich ohne Gesicht. \\
\hline The vivid tulips eat my oxygen. & Die lebhaften Tulpen essen meine Sauerstoff auf. & Die lebhaften Tulpen essen meine Sauerstoff auf. \\
\hline Before they came the air was calm enough, & Bevor sie kamen, war die Luft still genug, & Bevor sie kamen, war die Luft still genug, \\
\hline $\begin{array}{l}\text { Coming and going, breath by breath, without any } \\
\text { fuss. }\end{array}$ & Kam und ging, Atem um Atem, ohne Getue. & Kam und ging, Atem um Atem, ganz ohne Getue. \\
\hline Then the tulips filled it up like a loud noise. & Dann füllten die Tulpen sie wie ein lauter Lärm. & Dann füllten die Tulpen sie wie ein lauter Lärm. \\
\hline $\begin{array}{l}\text { Now the air snags and eddies round them the way } \\
\text { a river }\end{array}$ & $\begin{array}{l}\text { Nun schlägt die luft Wellen um sie und stößt an sie wie ein } \\
\text { Fluß }\end{array}$ & Nun wirbelt und kräuselt die Luft sich rund um wie ein Fluß \\
\hline
\end{tabular}




\begin{tabular}{|c|c|c|}
\hline ORIGINAL & 1. ${ }^{a}$ VERSIÓN & CORRECCIONES \\
\hline $\begin{array}{l}\text { Snags and eddies round a sunken rust-red } \\
\text { engine. }\end{array}$ & $\begin{array}{l}\text { Wellen schlägt und sich kräuselt um eine gesunkene } \\
\text { rostigrote Maschine }\end{array}$ & Sich wirbelt und kräuselt eine gesunkene rostigrote Maschine. \\
\hline They concentrate my attention, that was happy & $\begin{array}{l}\text { Sie ziehen meine Aufmerksamkeit auf sich, die glücklich } \\
\text { war. }\end{array}$ & Sie sammeln meine Aurmerksamkeit, die froh war \\
\hline Playing and resting without committing itself. & Zu spielen und zu rasten ohne geben der zu sein. & Zu spielen und zu rasten ohne sich dabei zu binden. \\
\hline The walls, also, seem to be warming themselves. & Auch die Wände scheinen sich zu erwärmen. & Auch die Wände scheinen sich zu erwärmen. \\
\hline $\begin{array}{l}\text { The tulips should be behind bars like dangerous } \\
\text { animals; }\end{array}$ & Die tulpen sollten hinter Gittern sein wie gefährliche Tiere; & Die Tulpen gehören hinter Gitter wie gefährliche Tiere; \\
\hline $\begin{array}{l}\text { They are opening like the mouth of some great } \\
\text { African cat, }\end{array}$ & $\begin{array}{l}\text { Sie öfnen sich wie das Maul einer großen afrikanischen } \\
\text { Katze }\end{array}$ & Sie öfnen sich wie das Maul einer großen afrikanischen Katze. \\
\hline And I am aware of my heart: it opens and closes & Und ich bemerke mein Herz: es öffnet und schließt & Und ich bemerke mein Herz: es öffnet und schließt \\
\hline Its bowl of red blooms out of sheer love of me. & Seine Schale von roten Blumen aus purer Liebe zu mir. & Seine Schale von roten Blumen aus purer Liebe zu mir. \\
\hline The water I taste is warm and salt, like the sea, & $\begin{array}{l}\text { Das Wasser, das ich koste, ist warm und salzig, wie } \\
\text { Meerwasser. }\end{array}$ & $\begin{array}{l}\text { Das Wasser, das ich koste, ist warm und sazig wie } \\
\text { Meerwasser }\end{array}$ \\
\hline And comes from a country far away as health. & $\begin{array}{l}\text { Und kommt von einem Land, das so weit ist wie die } \\
\text { Gesundheit. }\end{array}$ & $\begin{array}{l}\text { Und kommt aus einem Land, das so fern ist wie die } \\
\text { Gesundheit. }\end{array}$ \\
\hline
\end{tabular}




\begin{tabular}{|c|c|c|c|}
\hline ORIGINAL & 2. VERSIÓN & CORRECCIONES & 3. ${ }^{a}$ VERSIÓN (POSIBLE ENTREGADA) \\
\hline & Tulpen & & Tulpen \\
\hline The tulips are too excitable, it is winter here. & Die Tulpen sind zu erregbar, es ist hier Winter. & & Die Tulpen sind zu erregbar, es ist hier Winter. \\
\hline $\begin{array}{l}\text { Look how white everything is, how quiet, how } \\
\text { snowed-in. }\end{array}$ & Sien wie weilß alles ist, wie still, wie eingeschneit. & & Sieh wie weil alles ist, wie still, wie eingeschneit. \\
\hline I am learning peacefulness, lying by myself quietly & Ich lerne Friedlichkeit, Alleinliegen, ruhig & & Ich lerne Friedlichkeit, Alleinliegen, ruhig \\
\hline $\begin{array}{l}\text { As the light lies on these white walls, this bed, } \\
\text { these hands. }\end{array}$ & $\begin{array}{l}\text { Wie das Licht liegt auf diesen weiBen Wänden, diesem } \\
\text { Bett, diesen Händen. }\end{array}$ & & $\begin{array}{l}\text { Wie das Licht liegt auf diesen weilien Wänden, } \\
\text { diesem Bett, diesen Händen. }\end{array}$ \\
\hline I am nobody; I have nothing to do with explosions. & $\begin{array}{l}\text { Ich bin niemand, ich habe nichts zu schaffen mit } \\
\text { Explosionen. }\end{array}$ & & $\begin{array}{l}\text { Ich bin niemand, ich habe nichts zu schaffen mit } \\
\text { Explosionen. }\end{array}$ \\
\hline $\begin{array}{l}\text { I have given my name and my day-clothes up to } \\
\text { the nurses }\end{array}$ & $\begin{array}{l}\text { Ich habe meinen Namen und meine Tagess/eider den } \\
\text { Schwestern gegeben, }\end{array}$ & & $\begin{array}{l}\text { Ich habe meinen Namen und meine Tages lieider } \\
\text { den Schwestern gegeben, }\end{array}$ \\
\hline $\begin{array}{l}\text { And my history to the anesthetist and my body to } \\
\text { surgeons. }\end{array}$ & $\begin{array}{l}\text { Meine Geschichte dem Anästhesisten und meinen Leib } \\
\text { den Chinurgen. }\end{array}$ & & $\begin{array}{l}\text { Meine Geschichte dem Anästhesisten und } \\
\text { meinen Leib den Chirurgeen. }\end{array}$ \\
\hline $\begin{array}{l}\text { They have propped my head between the pillow } \\
\text { and the sheet-cuff }\end{array}$ & $\begin{array}{l}\text { Sie haben meinen Kopf aufgestellt zwischen Kissen und } \\
\text { Überschlaglaken }\end{array}$ & & $\begin{array}{l}\text { Sie haben meinen Kopf aufgestellt zwischen } \\
\text { Kissen und Überschlaglaken }\end{array}$ \\
\hline $\begin{array}{l}\text { Like an eye between two white lids that will not } \\
\text { shut. }\end{array}$ & $\begin{array}{l}\text { Wie ein Auge zwischen zwei weilien Lidern, die nicht } \\
\text { zufallen wollen. }\end{array}$ & & $\begin{array}{l}\text { Wie ein Auge zwischen zwei weiBen Lidern, die } \\
\text { nicht zuffallen wollen. }\end{array}$ \\
\hline Stupid pupil, it has to take everything in. & Dummer Schüler, es muß alles in sich autnehmen. & Dumme Pupille, sie muß alles in sich autnehmen. & Dumme Pupille, sie muß alles in sich aufnehmen. \\
\hline The nurses pass and pass, they are no trouble, & Die Schwestern gehen vorbei und vorbei, die stören nicht, & & $\begin{array}{l}\text { Die Schwestern gehen vorbei und vorbei, die } \\
\text { stören nicht, }\end{array}$ \\
\hline $\begin{array}{l}\text { They pass the way gulls pass inland in their white } \\
\text { caps, }\end{array}$ & $\begin{array}{l}\text { Sie gehen vorbei wie Möw en landen in ihren weilen } \\
\text { Hauben, }\end{array}$ & & $\begin{array}{l}\text { Sie gehen vorbei wie Möw en landen in ihren } \\
\text { weißen Hauben, }\end{array}$ \\
\hline $\begin{array}{l}\text { Doing things with their hands, one just the same } \\
\text { as another, }\end{array}$ & Tun etwas mit ihren Händen, jede genau wie die andre, & & $\begin{array}{l}\text { Tun etwas mit ihren Händen, jede genau wie die } \\
\text { andre, }\end{array}$ \\
\hline So it is impossible to tell how many there are. & So daß es unmöglich ist zu sagen wieviele es sind. & & $\begin{array}{l}\text { So dab es unmöglich ist zu sagen, wieviele es } \\
\text { sind. }\end{array}$ \\
\hline My body is a pebble to them, they tend it as water & $\begin{array}{l}\text { Mein Leib ist ein Kiesel für sie, sie pflegen ihn so, wie } \\
\text { Wasser }\end{array}$ & & $\begin{array}{l}\text { Mein Leib ist ein Kiesel für sie, sie plegen ihn so, } \\
\text { wie Wasser }\end{array}$ \\
\hline $\begin{array}{l}\text { Tends to the pebbles it must run over, smoothing } \\
\text { them gently. }\end{array}$ & $\begin{array}{l}\text { Kiesel pflegt, über die es fließen muß, und sie langsam } \\
\text { glättet sant. }\end{array}$ & $\begin{array}{l}\text { Kiesel ptlegt, über die es fließen muß, und sie } \\
\text { langsam santt glättet. }\end{array}$ & $\begin{array}{l}\text { Kiesel pflegt, über die es fließen muß und sie } \\
\text { santi glättet. }\end{array}$ \\
\hline $\begin{array}{l}\text { They bring me numbness in their bright needles, } \\
\text { they bring me sleep. }\end{array}$ & $\begin{array}{l}\text { Sie bringen mir Stumptheit in ihren blanken Nadeln, sie } \\
\text { bringen mir Schlat. }\end{array}$ & & $\begin{array}{l}\text { Sie bringen mir Stumptheit in ihren blanken } \\
\text { Nadeln, sie bringen mir Schlaf. }\end{array}$ \\
\hline
\end{tabular}




\begin{tabular}{|c|c|c|c|}
\hline ORIGINAL & $2^{\mathrm{a}}$ VERSIÓN & CORRECCIONES & 3. ${ }^{a}$ VERSIÓN (POSIBLE ENTREGADA) \\
\hline Now I have lost myself I am sick of baggage-- & $\begin{array}{l}\text { Nun hab ich mich selbst verloren und jedes Gepäck macht } \\
\text { mich krank - }\end{array}$ & & $\begin{array}{l}\text { Nun hab ich mich selbst verloren, und jedes } \\
\text { Gepäck macht mich krank - }\end{array}$ \\
\hline $\begin{array}{l}\text { My patent leather overnight case like a black } \\
\text { pillbox, }\end{array}$ & Mein kleiner Lackkoffer wie eine schwarze Pillenschachtel. & & $\begin{array}{l}\text { Mein kleiner Lackkoffer wie eine schwarze } \\
\text { Pillenschachtel. }\end{array}$ \\
\hline $\begin{array}{l}\text { My husband and child smiling out of the family } \\
\text { photo; }\end{array}$ & $\begin{array}{l}\text { Mein Mann und mein Kind, die lächeln aus dem } \\
\text { Famillenfoto; }\end{array}$ & & $\begin{array}{l}\text { Mein Mann und mein Kind, dielächen aus dem } \\
\text { Famillenfotot; }\end{array}$ \\
\hline $\begin{array}{l}\text { Their smiles catch onto my skin, little smiling } \\
\text { hooks. }\end{array}$ & $\begin{array}{l}\text { Ihr Lächeln verfängt sich in meine Haut wie lächelnde } \\
\text { Haken. }\end{array}$ & & $\begin{array}{l}\text { Ihr Lächeln verfängt sich in meine Haut wie } \\
\text { lächelnde Haken. }\end{array}$ \\
\hline I have let things slip, a thirty-year-old cargo boat & $\begin{array}{l}\text { Ich hab alles treiben lassen, einen dreiligiähricigen } \\
\text { Lastkahn, }\end{array}$ & & $\begin{array}{l}\text { Ich hab alles treiben lassen, einen dreibigiährigen } \\
\text { Lastkahn, }\end{array}$ \\
\hline stubbornly hanging on to my name and address. & $\begin{array}{l}\text { Hartnäckig halte ich fest an meinem Namen und meiner } \\
\text { Adresse. }\end{array}$ & & $\begin{array}{l}\text { Hartnäckig halte ich fest an meinem Namen und } \\
\text { meiner Adresse. }\end{array}$ \\
\hline $\begin{array}{l}\text { They have swabbed me clear of my loving } \\
\text { associations. }\end{array}$ & $\begin{array}{l}\text { Sie haben mich reingeschrubbt von allen Bindungen } \\
\text { meiner Liebe. }\end{array}$ & & $\begin{array}{l}\text { Sie haben mich reingeschrubbt von allen } \\
\text { Bindungen meiner Liebe. }\end{array}$ \\
\hline $\begin{array}{l}\text { Scared and bare on the green plastic-pillowed } \\
\text { trolley }\end{array}$ & $\begin{array}{l}\text { Verängstigt und nackt auf dem grünen Rol lwagen mit' } \\
\text { Plastikkissen. }\end{array}$ & & $\begin{array}{l}\text { Verängstigt und nackt auf dem grünen Rol wagen } \\
\text { mit Plastikkissen. }\end{array}$ \\
\hline $\begin{array}{l}\text { I watched my teaset, my bureaus of linen, my } \\
\text { books }\end{array}$ & $\begin{array}{l}\text { Ich sah mein Teeservice, meinen Wäscheschrank, meine } \\
\text { Bücher }\end{array}$ & & $\begin{array}{l}\text { Ich sah mein Teeservice, meinen Wäscheschrank, } \\
\text { meine Bücher }\end{array}$ \\
\hline $\begin{array}{l}\text { Sink out of sight, and the water went over my } \\
\text { head. }\end{array}$ & $\begin{array}{l}\text { AuBer Sicht sinken, und das Wasser steigen, mir über den } \\
\text { Kopf. }\end{array}$ & & $\begin{array}{l}\text { Außer Sicht sinken, und das Wasser steigen, mir } \\
\text { über den Kopt. }\end{array}$ \\
\hline I am a nun now, I have never been so pure. & Ich bin eine Nonne jetzt, nie noch war ich so rein. & & Ich bin eine Nonne jetzt, nie noch war ich so rein. \\
\hline I didn't want any flowers, I only wanted & Ich wollte keine Blumen, ich wollte nur & & Ich wollte keine Blumen, ich wollte nur \\
\hline $\begin{array}{l}\text { To lie with my hands turned up and be utterly } \\
\text { empty. }\end{array}$ & So liegen, Handteller nach oben, und ganz leer sein. & & $\begin{array}{l}\text { So liegen, Handteller nach oben, und ganz leer } \\
\text { sein. }\end{array}$ \\
\hline How free it is, you have no idea how free-- & Wie frei das ist. Ihr habt keine Ahnung, wiefrei. - & & Wiefrei das ist. Ihr habt keine Ahnung, wiefrei. - \\
\hline The peacefulness is so big it dazes you, & Der Friede ist so groß, daß er einen betäubt. & & Der Friede ist so groß, daß er einen betäubt. \\
\hline And it asks nothing, a name tag, a few trinkets. & $\begin{array}{l}\text { Und er will nichts, nur den Namen an Arm und ein wenig } \\
\text { Kleinkram. }\end{array}$ & & $\begin{array}{l}\text { Und er will nichts, nur den Namen an Amm und ein } \\
\text { wenig Kleinkram. }\end{array}$ \\
\hline $\begin{array}{l}\text { It is what the dead close on, finally;; I imagine } \\
\text { them }\end{array}$ & $\begin{array}{l}\text { Damit begnügen sich die Toten am Ende: ich siell sie mir } \\
\text { vor. }\end{array}$ & & $\begin{array}{l}\text { Damit begnügen sich die Toten am Ende: ich siell } \\
\text { sie mir vor. }\end{array}$ \\
\hline $\begin{array}{l}\text { Shutting their mouths on it, like a Communion } \\
\text { tablet. }\end{array}$ & $\begin{array}{l}\text { Das unschließen sie mit ihrem Mund wie nach der Beichte } \\
\text { eine Oblate. }\end{array}$ & & $\begin{array}{l}\text { Das umschließen sie mit ihrem Mund wie nach } \\
\text { der Beichte eine Oblate. }\end{array}$ \\
\hline
\end{tabular}




\begin{tabular}{|c|c|c|c|}
\hline ORIGINAL & $2{ }^{a}$ VERSIÓN & CORRECCIONES & $3 .{ }^{a}$ VERSIÓN (POSIBLE ENTREGADA) \\
\hline $\begin{array}{l}\text { The tulips are too red in the first place, they hurt } \\
\text { me. }\end{array}$ & Die Tulpen sind erstens zu rot, sie tun mir weh. & & Die Tulpen sind erstens zu rot, sie tun mir weh. \\
\hline $\begin{array}{l}\text { Even through the gift paper I could hear them } \\
\text { breathe }\end{array}$ & $\begin{array}{l}\text { Selosi durch das Geschenkpapier konnte ich hören, wie } \\
\text { sie atmen, }\end{array}$ & & $\begin{array}{l}\text { Sellost durch das Geschenkpapier konnte ich } \\
\text { hören, wie sie atmen, }\end{array}$ \\
\hline $\begin{array}{l}\text { Lightly, through their white swaddlings, like an } \\
\text { awtul baby. }\end{array}$ & $\begin{array}{l}\text { Leicht, durch die weißse Umwicklung, wie ein furchtbares } \\
\text { Baby. }\end{array}$ & & $\begin{array}{l}\text { Leicht, durch die weiße Umwicklung, wie ein } \\
\text { furchtbares Baby. }\end{array}$ \\
\hline Their redness talks to my wound, it corresponds. & Ihr Rot spricht zu meiner Wunde, es entspricht ihr. & & $\begin{array}{l}\text { Ihr Rot spricht zu meiner Wunde, es entsporicht } \\
\text { ihr. }\end{array}$ \\
\hline $\begin{array}{l}\text { They are subtle : they seem to float, though they } \\
\text { weigh me down, }\end{array}$ & $\begin{array}{l}\text { Sie sind listig: sie scheinen zu schweben und drücken } \\
\text { mich doch nieder, }\end{array}$ & & $\begin{array}{l}\text { Sie sind listig: sie scheinen zu schweben und } \\
\text { drücken mich doch nieder, }\end{array}$ \\
\hline $\begin{array}{l}\text { Upsetting me with their sudden tongues and their } \\
\text { color, }\end{array}$ & $\begin{array}{l}\text { Beschweren mich mit ihren plözlichen Zungen und ihrer } \\
\text { Farbe }\end{array}$ & & $\begin{array}{l}\text { Beschweren mich mit ihren plötzichen Zungen } \\
\text { und ihrer Farbe }\end{array}$ \\
\hline \multirow[t]{2}{*}{ A dozen red lead sinkers round my neck. } & Ein Dutzend rote Bleilote um meinen Hals. & Ein Dutzend rote Senkbleie um meinen Hals. & Ein Dutzend rote Senkbleie um meinen Hals. \\
\hline & & & añadido a mano: $>---<$ neue Strophe \\
\hline Nobody watched me before, now I am watched. & Bisher war ich unbewacht, nun werde ich bewacht. & & $\begin{array}{l}\text { Bisher war ich unbewacht, nun werde ich } \\
\text { bewacht. }\end{array}$ \\
\hline The tulips tumn to me, and the window behind me & Die Tulpen wenden sich mir zu und hinter mir dem Fenster, & & $\begin{array}{l}\text { Die Tulpen wenden sich mir zu und hinter mir } \\
\text { dem Fenster, }\end{array}$ \\
\hline $\begin{array}{l}\text { Where once a day the light slowly widens and } \\
\text { slowly thins, }\end{array}$ & $\begin{array}{l}\text { Wo einmal am Tag das Licht langsam weiter wird und } \\
\text { langsam dünn wird, }\end{array}$ & & $\begin{array}{l}\text { Wo einmal am Tag das Licht langsam weiter und } \\
\text { langsam dünn wird, }\end{array}$ \\
\hline $\begin{array}{l}\text { And I see myself, flat, idiculous, a cut-paper } \\
\text { shadow }\end{array}$ & $\begin{array}{l}\text { Und ich sehe mich, flach, zum Lachen, ein papierener } \\
\text { Scherenschnittschatten. }\end{array}$ & & $\begin{array}{l}\text { Und ich sehe mich, flach, zum Lachen, ein } \\
\text { papierener Scherenschnittschatten, }\end{array}$ \\
\hline $\begin{array}{l}\text { Between the eye of the sun and the eyes of the } \\
\text { tulips, }\end{array}$ & Zwischen dem Auge der Sonne und den Augen der Tuppen, & & $\begin{array}{l}\text { Zwischen dem Auge der Sonne und den Augen } \\
\text { der Tulpen, }\end{array}$ \\
\hline $\begin{array}{l}\text { And I have no face, I have wanted to efface } \\
\text { myself. }\end{array}$ & Und ich hab kein Gesicht, ich wollte gesichtslos werden. & & $\begin{array}{l}\text { Und ich hab kein Gesicht, ich wollte gesichtslos } \\
\text { werden. }\end{array}$ \\
\hline The vivid tulips eat my oxygen. & Die lebhatten Tulpen essen meine Sauerstoff weg. & & $\begin{array}{l}\text { Die lebhatten Tulpen essen meine Sauerstoff } \\
\text { weg. }\end{array}$ \\
\hline Before they came the air was calm enough, & Bevor sie kamen, war die Lutt ruhig genug, & & Bevor sie kamen, war die Lutt ruhig genug, \\
\hline $\begin{array}{l}\text { Coming and going, breath by breath, without any } \\
\text { fuss. }\end{array}$ & Kam und ging, Atem um Atem, ganz ohne Umstand. & & $\begin{array}{l}\text { Kam und ging, Atem um Atem, ganz ohne } \\
\text { Umstand. }\end{array}$ \\
\hline Then the tulips filled it up like a loud noise. & Dann erfüllten die Tulpen sie wie ein lautes Geräusch. & & $\begin{array}{l}\text { Dann effüllten die Tuppen sie wie ein lautes } \\
\text { Geräusch. }\end{array}$ \\
\hline $\begin{array}{l}\text { Now the air snags and eddies round them the way } \\
\text { a river }\end{array}$ & Nun wirbelt und kräuselt die Lutt sich um sie wie ein FluB & $\begin{array}{l}\text { Nun dreht und schlingt die Luft sich um sie wie ein } \\
\text { FluB }\end{array}$ & $\begin{array}{l}\text { Nun dreht und schlingt die Luft sich um sie wie } \\
\text { ein Flußs }\end{array}$ \\
\hline
\end{tabular}




\begin{tabular}{|c|c|c|c|}
\hline ORIGINAL & $2{ }^{a}$ VERSIÓN & CORRECCIONES & 3. ${ }^{a}$ VERSIÓN (POSIBLE ENTREGADA) \\
\hline $\begin{array}{l}\text { Snags and eddies round a sunken rust-red } \\
\text { engine. }\end{array}$ & $\begin{array}{l}\text { Sich wirbelt und kräusselt um eine versunkene rostigrote } \\
\text { Maschine. }\end{array}$ & $\begin{array}{l}\text { Sich dreht und schlingt um eine versunkene rostrote } \\
\text { Maschine. }\end{array}$ & $\begin{array}{l}\text { Sich dreht und schlingt um eine versunkene } \\
\text { rositrote Maschine. }\end{array}$ \\
\hline They concentrate my attention, that was happy & Sie sammett meine Aufmerksamkeit, die froh war & & Sie sammelt meine Aufmerksamkeit, die froh wa \\
\hline Playing and resting without committing itself. & Zu spielen und zu rasten ohne sich festzulegen. & & Zu spielen und zu rasten ohne sich festzulegen. \\
\hline The walls, also, seem to be warming themselves. & Auch die Wände scheinen sich zu erwärmen. & & Auch die Wände scheinen sich zu erwämmen. \\
\hline $\begin{array}{l}\text { The tulips should be behind bars like dangerous } \\
\text { animals;' }\end{array}$ & Die Tulpen sollten hinter Gittern sein wie gefährliche Tiere; & & $\begin{array}{l}\text { Die Tulpen sollten hinter Gittern sein wie } \\
\text { gefährliche Tiere; }\end{array}$ \\
\hline $\begin{array}{l}\text { They are opening like the mouth of some great } \\
\text { African cat, }\end{array}$ & $\begin{array}{l}\text { Sie öfnen sich wie das Maul einer großen afinkanischen } \\
\text { Katze, }\end{array}$ & & $\begin{array}{l}\text { Sie öfnen sich wie das Maul einer großen } \\
\text { arrikanischen Katze, }\end{array}$ \\
\hline And l am aware of my heart: it opens and closes & $\begin{array}{l}\text { Und ich werde aufmerksam auf mein Herz' es öffnet und } \\
\text { schließt }\end{array}$ & & $\begin{array}{l}\text { Und ich werde aufmerksam auf mein Herz: es } \\
\text { öfnet und schließt }\end{array}$ \\
\hline Its bowl of red blooms out of sheer love of me. & Seine Schale von roten Blumen aus purer Liebe zu mir. & & $\begin{array}{l}\text { Seine Schale von roten Blumen aus purer Liebe } \\
\text { zu mir. }\end{array}$ \\
\hline The water I taste is warm and salt, like the sea, & $\begin{array}{l}\text { Das Wasser, das ich koste, ist wam und Salz, wie das } \\
\text { Meer, }\end{array}$ & & $\begin{array}{l}\text { Das Wasser, das ich koste, ist warm und Salz, } \\
\text { wie das Meer, }\end{array}$ \\
\hline And comes from a country far away as health. & Und kommt aus einem Land so fern wie die Gesundheit. & & $\begin{array}{l}\text { Und kommt aus einem Land so fern wie die } \\
\text { Gesundheit. }\end{array}$ \\
\hline
\end{tabular}




The tulips are too excitable, it is winter here.
Look how white everything is, how quiet, how
snowed-in.
I am learning peacefulness, lying by myself quietly
As the light lies on these white walls, this bed,
these hands.

I am nobody; I have nothing to do with explosions.

I have given my name and my day-clothes up to the nurses

And my history to the anesthetist and my body to surgeons.

\section{They have propped my head between the pillow} and the sheet-cuff

Like an eye between two white lids that will not shut.

Stupid pupil, it has to take everything in.

The nurses pass and pass, they are no trouble,

They pass the way gulls pass inland in their white caps,

Doing things with their hands, one just the same as another,

So it is impossible to tell how many there are.

My body is a pebble to them, they tend it as water Tends to the pebbles it must run over, smoothing them gently.

They bring me numbness in their bright needles, they bring me sleep. \begin{tabular}{l|l} 
Tulpen & Tulpen
\end{tabular}

Die Tulpen sind zu erregbar, es ist hier Winter. Die Tulpen sind zu erregbar, es ist Winter hier.

Sieh wie weiß alles ist, wie still, wie eingeschneit. Sieh wie weiß alles ist, wie ruhig, wie eingeschneit.

\begin{tabular}{l|l} 
Ich lerne Friedlichkeit, Alleinliegen, ruhig Ich lerne Friedlichkeit, Alleinliegen, ruhig
\end{tabular}

Wie das Licht liegt auf diesen weißen Wänden, Wie das Licht liegt auf dieser weißen Wand, diesem Bett, diesem Bett, diesen Händen. diesen Händen.

Ich bin niemand, ich habe nichts zu schaffen mit Ich bin niemand, ich habe nichts zu tun mit Explosionen. Explosionen.

Ich habe meinen Namen und meine Tageskleider den Ich habe meinen Namen und meine Tagkleider den Schwestern gegeben, Schwestern weggegeben,

Meine Geschichte dem Anästhesisten und meinen Meine Geschichte dem Anästhesisten und meinen Leib den Chirurgen. Körper den Chirurgen.

Sie haben meinen Kopf aufgestellt zwischen Kissen Sie haben meinen Kopf hochgeholt zwischen den Kissen und Überschlaglaken und Bettuch

Wie ein Auge zwischen zwei weißen Lidern, die nicht Wie ein Auge zwischen zwei weißen Lidern, die nicht zufallen wollen. zufallen wollen.

Dumme Pupille, sie muß alles in sich aufnehmen. Dumme Pupille, sie muß alles in sich aufnehmen.

Die Schwestern gehen vorbei und vorbei, die stören Die Schwestern eilen(?) vorbei und vorbei, sie stören nicht, nicht,

Sie gehen vorbei wie Möwen landen in ihren weißen Sie eilen(?) vorbei wie Möwen landen [cambia pero es Hauben, ilegible a qué] in ihren weißen Hauben,

Tun etwas mit ihren Händen, jede genau wie die andre,

Tun etwas mit ihren Händen, jede ganz ist wie die andre,

So daß es unmöglich ist zu sagen, wieviele es sind. So ist es unmöglich zu sagen, wieviele es sind.

Mein Leib ist ein Kiesel für sie, sie pflegen ihn so, Mein Körper ist ein Kiesel für sie, sie guten ihn so, wie wie Wasser Wasser

Kiesel pflegt, über die es fließen muß und sie sanft Die Kiesel hutet, über die es fließen muß und sie sanft glättet. glättet.

Sie bringen mir Stumpfheit in ihren blanken Nadeln, Sie bringen mir Stumpfheit in ihren blanken Nadeln, sie sie bringen mir Schlaf. bringen mir Schlaf. 


\begin{tabular}{|c|c|c|}
\hline ORIGINAL & 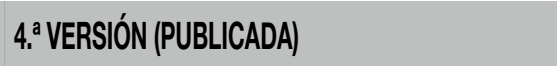 & CORRECCIÓN A LA PUBLICACIÓN \\
\hline Now I have lost myself I am sick of baggage - - & $\begin{array}{l}\text { Nun hab ich mich selbst verloren, und jedes Gepäck } \\
\text { macht mich krank - }\end{array}$ & $\begin{array}{l}\text { Nun daß ich mich selbst verloren habe, jedes macht } \\
\text { Gepäck mich krank - }\end{array}$ \\
\hline $\begin{array}{l}\text { My patent leather overnight case like a black } \\
\text { pillbox, }\end{array}$ & $\begin{array}{l}\text { Mein kleiner Lackkoffer wie eine schwarze } \\
\text { Pillenschachtel. }\end{array}$ & $\begin{array}{l}\text { Mein kleiner Lackkoffer wie eine schwarze } \\
\text { Pillenschachtel, }\end{array}$ \\
\hline $\begin{array}{l}\text { My husband and child smiling out of the family } \\
\text { photo; }\end{array}$ & $\begin{array}{l}\text { Mein Mann und mein Kind, die lächeln aus dem } \\
\text { Familienfoto; }\end{array}$ & Mein Mann und Kind, die lächeln aus dem Familienfoto; \\
\hline $\begin{array}{l}\text { Their smiles catch onto my skin, little smiling } \\
\text { hooks. }\end{array}$ & $\begin{array}{l}\text { Ihr Lächeln verfangen sich in meine Haut wie } \\
\text { lächelnde Haken. }\end{array}$ & $\begin{array}{l}\text { Ihre Lächeln verfangen sich in meine Haut wie } \\
\text { (corrección ilegible) lächelnde Haken. }\end{array}$ \\
\hline I have let things slip, a thirty-year-old cargo boat & $\begin{array}{l}\text { Ich hab alles treiben lassen, einen dreißigjährigen } \\
\text { Lastkahn, }\end{array}$ & Ich hab alles treiben lassen, ein dreißigjähriger Lastkahn, \\
\hline stubbornly hanging on to my name and address. & $\begin{array}{l}\text { Hartnäckig halte ich fest an meinem Namen und } \\
\text { meiner Adresse. }\end{array}$ & $\begin{array}{l}\text { ich verbissen festhält an meinem Namen und meiner } \\
\text { Adresse. }\end{array}$ \\
\hline $\begin{array}{l}\text { They have swabbed me clear of my loving } \\
\text { associations. }\end{array}$ & $\begin{array}{l}\text { Sie haben mich reingeschrubbt von allen Bindungen } \\
\text { meiner Liebe. }\end{array}$ & $\begin{array}{l}\text { Sie haben mich reingeschrubbt von den Bindungen } \\
\text { meiner Liebe. }\end{array}$ \\
\hline $\begin{array}{l}\text { Scared and bare on the green plastic-pillowed } \\
\text { trolley }\end{array}$ & $\begin{array}{l}\text { Verängstigt und nackt auf dem grünen Rollwagen } \\
\text { mit Plastikkissen. }\end{array}$ & $\begin{array}{l}\text { Verängstigt und nackt auf dem grünen plastikbezogene } \\
\text { (no estoy segura de que sea lo que pone) Rollwagen. }\end{array}$ \\
\hline $\begin{array}{l}\text { I watched my teaset, my bureaus of linen, my } \\
\text { books }\end{array}$ & $\begin{array}{l}\text { Ich sah mein Teeservice, meinen Wäscheschrank, } \\
\text { meine Bücher }\end{array}$ & $\begin{array}{l}\text { Ich sah mein Teeservice, meinen Wäscheschrank, meine } \\
\text { Bücher }\end{array}$ \\
\hline $\begin{array}{l}\text { Sink out of sight, and the water went over my } \\
\text { head. }\end{array}$ & $\begin{array}{l}\text { Außer Sicht sinken, und das Wasser steigen, mir } \\
\text { über den Kopf. }\end{array}$ & $\begin{array}{l}\text { Außer Sicht sinken, und das Wasser steig mir über den } \\
\text { Kopf. }\end{array}$ \\
\hline I am a nun now, I have never been so pure. & Ich bin eine Nonne jetzt, nie noch war ich so rein. & Ich bin eine Nonne jetzt, ich war noch nie so rein. \\
\hline I didn't want any flowers, I only wanted & Ich wollte keine Blumen, ich wollte nur & Ich wollte keine Blumen, ich wollte nur \\
\hline $\begin{array}{l}\text { To lie with my hands turned up and be utterly } \\
\text { empty. }\end{array}$ & So liegen, Handteller nach oben, und ganz leer sein. & Liegen, Handteller nach oben, und völlig leer. \\
\hline How free it is, you have no idea how free-- & Wie frei das ist. Ihr habt keine Ahnung, wie frei. - & Wie frei das ist. Du hast keine Ahnung, wie frei - \\
\hline The peacefulness is so big it dazes you, & Der Friede ist so groß, daß er einen betäubt. & Der Friede ist so groß, daß er dich betäubt, \\
\hline And it asks nothing, a name tag, a few trinkets. & $\begin{array}{l}\text { Und er will nichts, nur den Namen an Arm und ein } \\
\text { wenig Kleinkram. }\end{array}$ & $\begin{array}{l}\text { Und er will nichts, den Namen am Arm und ein wenig } \\
\text { Kleinkram. }\end{array}$ \\
\hline $\begin{array}{l}\text { It is what the dead close on, finally; I imagine } \\
\text { them }\end{array}$ & $\begin{array}{l}\text { Damit begnügen sich die Toten am Ende: ich stell sie } \\
\text { mir vor. }\end{array}$ & $\begin{array}{l}\text { Damit befinden sich dieToten sich am Ende: ich stell sie } \\
\text { mir vor. }\end{array}$ \\
\hline $\begin{array}{l}\text { Shutting their mouths on it, like a Communion } \\
\text { tablet. }\end{array}$ & $\begin{array}{l}\text { Das umschließen sie mit ihrem Mund wie nach der } \\
\text { Beichte eine Oblate. }\end{array}$ & $\begin{array}{l}\text { Das umschließen sie mit ihrem Mund wie nach der } \\
\text { Beichte die Oblate. }\end{array}$ \\
\hline
\end{tabular}


The tulips are too red in the first place, they hurt me.

Even through the gift paper I could hear them breathe

Lightly, through their white swaddlings, like an awful baby.

Their redness talks to my wound, it corresponds.

They are subtle : they seem to float, though they weigh me down,

Upsetting me with their sudden tongues and their color,

A dozen red lead sinkers round my neck.

Nobody watched me before, now I am watched.

The tulips turn to me, and the window behind me

Where once a day the light slowly widens and slowly thins,

And I see myself, flat, ridiculous, a cut-paper shadow

Between the eye of the sun and the eyes of the tulips,

And I have no face, I have wanted to efface myself.

The vivid tulips eat my oxygen.

Before they came the air was calm enough,

Coming and going, breath by breath, without any fuss.

Then the tulips filled it up like a loud noise.

Now the air snags and eddies round them the way a river
Die Tulpen sind erstens zu rot, sie tun mir weh.

Die Tulpen sind erstens zu rot, sie haben mir zu weh getan.

Selbst durch das Geschenkpapier konnte ich hören, Selbst durch das Geschenkpapier konnte ich hören, sie wie sie atmen, atmen,

Leicht, durch die weiße Umwicklung, wie ein furchtbares Baby.

Leicht, durch die weiße Umwicklung, wie ein furchtbares Baby.

Ihr Rot spricht zu meiner Wunde, es entspricht ihr. Ihre Rotte spricht zu meiner Wunde, sie entspricht ihr.

Sie sind listig: sie scheinen zu schweben und drücken mich doch nieder,

Sie sind listig: sie scheinen zu schweben und drücken mich doch nieder,

Beschweren mich mit ihren plötzlichen Zungen und Beschweren mich mit ihren plötzlichen Zungen und ihrer ihrer Farbe, Farbe,

Ein Dutzend rote Senkbleie um meinen Hals. Ein Dutzend rote Senkbleie um meinen Hals.

Bisher war ich unbewacht, nun werde ich bewacht. Bisher haben sie mich nicht bewacht, jetzt werde ich bewacht.

Die Tulpen wenden sich mir zu und hinter mir dem Die Tulpen wenden sich mir zu und hinter mir dem Fenster, Fenster,

Wo einmal am Tag das Licht langsam weiter und Wo einmal am Tag das Licht langsam weiter und langsam dünner wird,

Und ich sehe mich, flach, zum Lachen, ein papierener Scherenschnittschatten, langsam dünner wird

Und ich sehe mich, flach, zum Lachen, ein papierener Scherenschnittschatten,

Zwischen dem Auge der Sonne und den Augen der Zwischen dem Auge der Sonne und den Augen der Tulpen, Tulpen,

Und ich hab kein Gesicht, ich wollte gesichtslos Und ich hab kein Gesicht, ich wollte gesichtslos werden. werden.

Die lebhaften Tulpen essen meine Sauerstoff. Die lebhaften Tulpen essen meinen Sauerstoff.

Bevor sie kamen, war die Luft ruhig genug,

Bevor sie kamen, war die Luft ruhig genug,

Kam und ging, Atem um Atem, ganz ohne Umstand. Kam und ging, Atem um Atem, ganz ohne Umstand.

Dann erfüllten die Tulpen sie wie ein lautes

Dann erfültten die Tulpen sie wie ein lautes Geräusch. Geräusch.

Nun dreht und schlingt die Luft sich um sie wie ein Nun dreht und schlingt die Luft sich um sie wie ein Fluß FluB 


\begin{tabular}{|c|c|c|}
\hline ORIGINAL & 4. ${ }^{\text {V VERSIÓN (PUBLICADA) }}$ & CORRECCIÓN A LA PUBLICACIÓN \\
\hline $\begin{array}{l}\text { Snags and eddies round a sunken rust-red } \\
\text { engine. }\end{array}$ & $\begin{array}{l}\text { Sich dreht und schlingt um eine versunkene rostrote } \\
\text { Maschine. }\end{array}$ & $\begin{array}{l}\text { Sich dreht und schlingt um eine versunkene rostrote } \\
\text { Maschine. }\end{array}$ \\
\hline They concentrate my attention, that was happy & Sie sammelt meine Aufmerksamkeit, die froh war & Sie sammelt meine Aufmerksamkeit, die froh war \\
\hline Playing and resting without committing itself. & Zu spielen und zu rasten ohne sich festzulegen. & Zu spielen und zu rasten ohne sich festzulegen. \\
\hline The walls, also, seem to be warming themselves. & Auch die Wände scheinen sich zu erwärmen. & Auch die Wände scheinen sich zu erwärmen. \\
\hline $\begin{array}{l}\text { The tulips should be behind bars like dangerous } \\
\text { animals; }\end{array}$ & $\begin{array}{l}\text { Die Tulpen sollten hinter Gittern sein wie gefährliche } \\
\text { Tiere; }\end{array}$ & $\begin{array}{l}\text { Die Tulpen sollten hinter Gittern sein wie gefährliche } \\
\text { Tiere; }\end{array}$ \\
\hline $\begin{array}{l}\text { They are opening like the mouth of some great } \\
\text { African cat, }\end{array}$ & $\begin{array}{l}\text { Sie öffnen sich wie das Maul einer großen } \\
\text { afrikanischen Katze, }\end{array}$ & $\begin{array}{l}\text { Sie öffnen sich wie das Maul einer großen afrikanischen } \\
\text { Katze, }\end{array}$ \\
\hline And I am aware of my heart: it opens and closes & $\begin{array}{l}\text { Und ich werde aufmerksam auf mein Herz: es öffnet } \\
\text { und schließt }\end{array}$ & $\begin{array}{l}\text { Und ich werde aufmerksam auf mein Herz: es öffnet unc } \\
\text { schließt }\end{array}$ \\
\hline Its bowl of red blooms out of sheer love of me. & $\begin{array}{l}\text { Seine Schale von roten Blumen aus purer Liebe zu } \\
\text { mir. }\end{array}$ & Seine Schale von roten Blumen aus purer Liebe zu mir. \\
\hline The water I taste is warm and salt, like the sea, & $\begin{array}{l}\text { Das Wasser, das ich koste, ist warm und Salzig, wie } \\
\text { das Meer, }\end{array}$ & $\begin{array}{l}\text { Das Wasser, das ich koste, ist warm und salzig, wie das } \\
\text { Meer, }\end{array}$ \\
\hline And comes from a country far away as health. & $\begin{array}{l}\text { Und kommt aus einem Land so fern wie die } \\
\text { Gesundheit. }\end{array}$ & Und kommt aus einem Land so fern wie Gesundheit. \\
\hline
\end{tabular}


Anexo II

ARIEL - FEVER $103^{\circ}-39,5^{\circ}$ FIEBER

\begin{tabular}{|c|c|c|c|}
\hline ORIGINAL & 1. ${ }^{a}$ VERSIÓN & CORRECCIONES & $2 .{ }^{a}$ VERSIÓN \\
\hline Fever $103^{\circ}$ & $39.5^{0}$ Fieber & $39.5^{\circ}$ Fieber & $\underline{39.5^{\circ} \text { Fieber }}$ \\
\hline Pure? What does it mean? & Rein? Was bedeutet das? & Rein? Was bedeutet das? & Rein? Was bedeutet das? \\
\hline The tongues of hell & Die Zunge der Hölle & Die Zungen der Hölle & Die Zungen der Hölle \\
\hline Are dull, dull as the triple & Sind dumpt, dumpf wie die dreifache & Sind dumpt, dumpf wie die dreiflatige & Sind stumpt, stumpf wie die dreiffachen \\
\hline Tongues of dull, fat Cerberus & Zunge des dumpfen fetten Zerberus & Zunge des dummen, fetten Zerberus & Zungen des stumpfen, fetten Zerberus \\
\hline Who wheezes at the gate. Incapable & der schnauft am Tor. Unfähig & Der keucht am Tor. & Der keucht am Tor. Nicht fähig \\
\hline Of licking clean & Unfähig, rein zulecken & Unfähig, reinzulecken & Reinzulecken die Wunde \\
\hline The aguey tendon, the sin, the sin. & Die schmerzhatte Sehne, die Sünde, die Sünde. & Die schmerzhafte Sehne, die Sünde, die Sünde. & Die fiebrige Sehne, die Sünde, die Sünde. \\
\hline The tinder cries. & Der Zunder schreit. & Der Zunder schreit. & Der Zunder schreit. \\
\hline The indeleble smell & Der unanslöschbare Geruch & Der unanslöschbare Geruch & Der unanslöschbare Geruch \\
\hline Of a snuffed candle! & Einer geschneuzten Kerze! & Einer ausgeschneuzten Kerze! & Einer ausgeschneuzten Kerze!! \\
\hline Love, love, the low smokes roll & Liebe, Liebe, die niedrigen Rauchschwaden & $\begin{array}{l}\text { Lieber, Lieber, die niedrigen Rauchschwaden } \\
\text { laufen/rollen }\end{array}$ & $\begin{array}{l}\text { Lieber, Lieber! die schweren Rauchschwaden } \\
\text { rollen }\end{array}$ \\
\hline \multirow[t]{2}{*}{ From me like Isadora's scarves, I'm in a fright } & Fort von mir wie Isadoras Schal, ich bin voll Angst: & $\begin{array}{l}\text { Fort von mir wie Isadoras Schals, daß michAngst } \\
\text { macht/ich hab Angst, }\end{array}$ & Fort von mir wie Isadoras Schal, ich habe Angst: \\
\hline & & & estas dos estrofas aparecen como solo una \\
\hline One scarf will catch and anchor in the wheel. & $\begin{array}{l}\text { Ein Ende wird sich verfangen und sich im im Rad } \\
\text { verankern. }\end{array}$ & $\begin{array}{l}\text { Ein Schub wird sich verfangen und im Rad wird } \\
\text { sich verankern. }\end{array}$ & Ein Ende wird sich verfangen und ankern im Rad. \\
\hline Such yellow sullen smokes & So gelbe schwere Schwaden & So gelbe schwere Schwaden & So gelbe schwere Schwaden \\
\hline Make their own element. They will not rise, & Machen ihr eigenes Element. Die steigen nicht auf & Machen ihr eigenes Element. Die steigen nicht & Machen ihr eigenes Element. Sie steigen nicht auff \\
\hline But trundle round the globe & Sondern trudeln um den Erdball, & Sondern trudeln noch um den Erdball, & Sondern turndeln rund um den Erdball \\
\hline Choking the aged and the meek, & Ersticken die Alten und Schwachen (die zarten & Ersticken die Alten und Krüppeln sanft & Und ersticken die Alten und Schwächlichen, \\
\hline The weak & Das schwache & Das schwache & Das gebrechliche \\
\hline Hothouse baby in its crib, & Glashausbaby in seiner Krippe; die gräBliche & Glashausbaby in seiner Krippe; & Treibhausbaby in seiner Krippe: \\
\hline The ghastly orchid & Die gräsliche Orchidee & Die gräbliche Orchidee & Die gräsliche Orchidee \\
\hline Hanging its hanging garden in the air, & Die ihren hängenden Garten in die Luth hängt, - & Hangt ihren hängenden Garten in die Luft, - & Hängt ihren hängenden Garten in die Luft, \\
\hline
\end{tabular}




\begin{tabular}{|c|c|c|c|}
\hline ORIGINAL & 1. ${ }^{a}$ VERSIÓN & CORRECCIONES & $2 .{ }^{a}$ VERSIÓN \\
\hline Devilish leopard! & Teufflischer Leopard! & Teuflischer Leopard! & Teuflischer Leopard! \\
\hline Radiation turned it white & Die Strahlung machte es weiß & Die Strahlen hat sie weil/gebleicht noch & Die Strahlung hat es weils \\
\hline And killed it in an hour. & und tötete es in einer Stunde. & gemacht und umgebracht in einer Stunde. & Gemacht und umgebracht in einer Stunde. \\
\hline Greasing the bodies of adulterers & Sie fetten die Körper (Leiber) von Ehebrechern ein & Die fetten Leiber von Ehebrechern ein & Sie fettet die Leiber der Ehebrecher ein. \\
\hline Like Hiroshima ash and eating in. & Wie Hiroschima-Asche und freuen sich ein. & Wie Hiroschima-Asche und freuen sich ein. & $\begin{array}{l}\text { Wie Hiroschima-Asche und fri'Bt sich in Haut und } \\
\text { Rinde. }\end{array}$ \\
\hline The sin. The sin. & Die Sünde. Die Sünde. & Die Sünde. Die Sünde. Runde & Die Sünde. Die Sünde. \\
\hline Darling, all night & Liebster, die ganze Nacht & Liebster, die ganze Nacht & Liebster, die ganze Nacht \\
\hline I have been flickering, off, on, off, on. & Hab ich gefackert, tief, hoch, tief, hoch. & Hab ich geflackert, aus, an, aus, an. & Hab ich geflackert, aus, an, aus, an. \\
\hline The sheets grow heavy as a lecher's kiss. & $\begin{array}{l}\text { Die Bettücher werden schwer wie eines Wüstlings } \\
\text { Kuß. }\end{array}$ & $\begin{array}{l}\text { Die Bettücher werden schwer wie eines Wüstlings } \\
\text { KuB. }\end{array}$ & Schwer wird das Bettzeug wie ein Wüstlingskuß. \\
\hline Three dayss, Three nights. & Drei Tage, drei Nächte, & Drei Tage, drei Nächte, & Drei Tage. Drei Nächte. \\
\hline Lemon water, chicken & Wasser aus Zitronen, Wasser aus Huhn & Wasser aus Zitronen, Wasser aus Huhn & Zitronenwasser, Hühner- \\
\hline Water, water make me retch. & Wasser macht mich erbrechen (würgen.) & Wasser macht mich erbrechen & wasser, Wasser macht mich erbrechen. \\
\hline I am too pure for you or anyone. & Ich bin zu rein für dich oder irgendwen. & Ich bin zu rein für dich oder rigendwen. & Ich bin zu rein für dich oder irgendwen. \\
\hline Your body & Dein Körper & Dein Körper Leilh & Dein Körper \\
\hline Hurts me as the world hurts God. I am a lantern - & $\begin{array}{l}\text { schmerzt mich wie die Welt Gott schmerzt. Ich bin } \\
\text { eine Larterne - }\end{array}$ & $\begin{array}{l}\text { schmerzt mich wie die Welt Gott schmerzt. Ich bin } \\
\text { eine Laterne - }\end{array}$ & $\begin{array}{l}\text { Schmerzt mich wie die Welt Gott. Ich bin eine } \\
\text { Laterne - }\end{array}$ \\
\hline My head a moon & Mein Kopf ein Mond & Mein Kopf ein Mond & Mein Kopf ein Mond \\
\hline Of Japanese paper, my gold beaten skin & Aus Japanpapier, mein geschlagenden Goldhaut & Aus Japanpapier, meine geschlagende Goldhaut & Aus Japanpapier, meine geschlagene Goldhaut \\
\hline Infinitely delicate and infinitely expensive. & Unendlich zart und unendlich kostbar. & Unendlich zart und auch unendlich teuer. & Unendlich zart und auch unendlich Kostbar. \\
\hline Does not my heat astound you. And my light. & Erstaunt dich nicht meine Hitze. Und mein Licht. & $\begin{array}{l}\text { Verblutt Erstaunt dich nicht meine Hitze. Und mein } \\
\text { Licht. }\end{array}$ & Erstaunt dich meine Hitze nicht. Mein Licht. \\
\hline All by myself I am a huge camellia & $\begin{array}{l}\text { Ganz alleinfür mich bin ich eine ganz große Kamelie } \\
\text { (riesengroße }\end{array}$ & Allein bin ich eine ganz riesengroße Kamelie & Ich bin allein und bin eine große Kamelie \\
\hline
\end{tabular}




\begin{tabular}{|c|c|c|c|}
\hline ORIGINAL & 1. VERSIÓN & CORRECCIONES & 2.'VERSIÓN \\
\hline \multirow[t]{2}{*}{ Glowing and coming and going, flush on flush. } & $\begin{array}{l}\text { Glïhend und kommend und gehend, Wallung um } \\
\text { Wallung. }\end{array}$ & Glühend und kommend und gehend, Flut um Flut. & Und glüh und komm und gehe, Fut um Flut. \\
\hline & & & I. (y en p. siguiente)(39.50 Fieber, Blatt 2) \\
\hline Ithink l am going up, & Ich glaub, ich gehe hoch, & Ich glaub, ich gehe hoch, & Ich glaub, ich gehe hoch, \\
\hline Ithink I may rise - & Ich glaub, Ich kann mich erheben - & Ich glaub, Ich kann mich erheben - & Ich glaub, ich Könnte steigen - \\
\hline The beads of hot metal fly, and I, love, I & Die Rosenkranzperlen aus heiBem Metall & Die Rosenkranzperlen aus heiBem Metall & Die Rosenkranzperlen aus heiBem Metall \\
\hline Am a pure acetylene & Heben sich, und ich, Liebster, ich & Heben sich, und ich, Liebster, ich & Flegen, - und ich, Liebster, ich \\
\hline Virgin & Bin eine reine Acetylen- & Bin eine reine Actylen- & Bin eine reine Actyly- \\
\hline Attended by roses, & Jungariau, umhegt von Rosen, & Jungriau, umhegt von Rosen, & junghirau, von Rosen geleitet \\
\hline By kisses, by cherubim, & Von KüBen, von Cherubim, & Von Küssen, von Cherubim, & Von Kïssen, von Cherubim, \\
\hline By whatever the pink things mean. & Von was immer diese rosa Dinger bedeuten & Was immer diese rosa Dinger bedeuten, & Von was immer diese rosa Dinger bedeuten, \\
\hline Notyou, nor him & Nicht dir, noch him & Nicht dir, noch ihm & Nicht dir, nicht ihm, \\
\hline Nothim, nor him & Nicht ihm, noch ihm, & Nicht ihm, noch ihm, & Nicht ihm, noch ihm \\
\hline (My selves dissolving, old whore petticoats) - & $\begin{array}{l}\text { (meine Selbste lösen sich auf, alte Hurenunterröcke) } \\
\text { - }\end{array}$ & $\begin{array}{l}\text { (meine Selbste lösen sich auf, alte } \\
\text { Hurenunterröcke) - }\end{array}$ & $\begin{array}{l}\text { (Meine Selbste losen sich auf, atte } \\
\text { Hurenunteröocke) }\end{array}$ \\
\hline To Paradise. & Ins Paradies. & Ins Paradies. & Ins Paradies. \\
\hline
\end{tabular}




\begin{tabular}{|c|c|c|c|}
\hline ORIGINAL & CORRECCIONES & 3. ${ }^{2}$ VERSIÓN(POSBBLE ENTREGADA) & 4. ${ }^{a}$ VERSIÓN(PUBLLCADA) \\
\hline Fever $103^{\circ}$ & $39.5^{\circ}$ Fieber & $39.5^{\circ}$ Fieber & $39,5^{\circ}$ Fieber \\
\hline Pure? What does it mean? & Rein? Was bedelutetdas? & Rein? Was bededutet das? & Rein? Was bededutet das? \\
\hline The tongues of hell & Die Zungen der Hölle & Diezungen der Hölle & Diezungen der Hölle \\
\hline Are dull, dull as the triple & Sind stumpi, stumpf wie die dreitache & Sind stumpt, stumpt wie die dreftache & Sind stumpi, stumpf wie die dreitache \\
\hline Tongues of dull, fat Cerberus & Zunge des stumpien, fetten Zerberus & Zunge des stumpfen, fetten Zerberus & Zunge des stumpfen, fetten Zerberus \\
\hline Who wheezes at the gate. Incapable & Der Keuchtam Tor. Nicht fähig & Der keucht am Tor Nichtfähig & Der Keucht am Tor Nicht fähig \\
\hline Of licking clean & Reinzulecken die Wunde & Reinzulecken die Wunde, & Reinzulecken die Wunde, \\
\hline The aguey tendon, the sin, the sin. & Die fiebrige Sethe, die Sünde, die Sünde. & Diefiebrige Sethe, die Sünde, die Sünde. & Diefiebrige Sethne, die Sünde, die Sünde. \\
\hline The tinder cries. & Der Zunder schreit. & Der Zunder schreit. & Der Zunder schreit. \\
\hline The indeleble smell & Der una slosschbare Geruch & Der una slöschbare Geruch & Der una slosschbare Geruch \\
\hline Of a snuffed candle! & Einer ausgeschneuzten Kerz.! & Ener ausgeschneuzten Kerze!! & Einer ausgeschneuten Kerzel \\
\hline Love, love, the low smokes roll & Lieber, Lieber! die schweren Rauchschwaden rollen & Lieber, Lieberl die schweren Rauchschwaden rollen & Lieber, Lieberl die schweren Rauchsschwaden rollen \\
\hline \multirow[t]{2}{*}{ From me like Isadora's scarves, I'm in a fright } & Fot von mir wie lsadoras Schal; ich habe Angst: & Fort von mir we esadooras Schal; ich habe Angost: & Fort von mir wiel ssadoras Schad; ;ch habe Angsti: \\
\hline & separadas a mano con $>--<$ & separadas a mano con $>--<$ Zwischenraum! & \\
\hline One scarf will catch and anchor in the wheel. & Ein Ende wird sich verfangen und ankem im Rad. & Ein Ende wird sich verfangen und ankern im Rad. & Ein Ende wird sich verfangen und ankern im Rad. \\
\hline Such yellow sullen smokes & So gelbe schwere Schwaden & So gelbe schwere Schwaden & Sogetbetiribe Schwaden \\
\hline Make their own element They will not rise, & Machen ihr eigenes Element. Sie steigen nicht auff & Machen ihr eigenes Element. Sie steigen nicht auff & Machen ihr eigenes Element. Sie steigen nicht auf \\
\hline But trundle round the globe & Sondem truden rund um den Eraball & Sondem tudelen rund um den Eraball & Sondern tudelen rund um den Eraball \\
\hline Choking the aged and the meek, & Und ersiticken die Atten und Schwäachlichen, & Und ersicicken die Alten und Schwäachlichen, & Und essicicken die Alten und Schwäachlichen, \\
\hline The weak & Das gebrechliche & Das gebrechliche & Das gebrechliche \\
\hline Hothouse baby in its crib, & Treibhausbaboy in seiner Krippe: & Treibhausbaby in seiner Krippe: & Treibhausbabo i in seiner Krippe: \\
\hline The ghastly orchid & Die gräbiliche Orchidee & Die gräbliche Orchidee & Die gräliliche Orchicee \\
\hline Hanging its hanging garden in the air, & Hängt hiren hängenden Garten in die Lutt, & Hängt hiren hänngenden Garten in die Lutt, & Hängt hreen hängenden Garten in die Lut, \\
\hline
\end{tabular}




\begin{tabular}{|c|c|c|c|}
\hline ORIGINAL & CORRECCIONES & $3 .{ }^{a}$ VERSIÓN (POSIBLE ENTREGADA) & 4. VERSIÓN(PUBLICADA) \\
\hline Devilish leopard! & Teuflischer Leopard! & Teuffischer Leopard! & Teuffischer Leopard! \\
\hline Radiation turned it white & Die Strahlung hat es weil & Die Strahlung hat es weils & Die Strahlung hat es weils \\
\hline And killed it in an hour. & Gemacht und umgebracht in einer Stunde. & Gemacht und umgebracht in einer Stunde. & Gemacht und umgebracht in einer Stunde. \\
\hline Greasing the bodies of adulterers & Sief fettet die Leiber der Ehebrecher ein. & Sie fettet die Leiber der Ehebrecher ein. & Sie fettet die Leiber der Ehebrecher ein. \\
\hline Like Hiroshima ash and eating in. & Wie Hiroschima-Asche und friBt sich in Haut und Rinde. & Wie Hiroshima-Asche und tríts sich in Haut und Rinde. & Wie Hiroshima-Asche und triBts sich in Haut und Rinde. \\
\hline The sin. The sin. & Die Sünde. Die Sünde. & Die Sünde. Die Sünde. & Die Sünde. Die Sünde. \\
\hline Darling, all night & Liebster, die ganze Nacht & Liebster, die ganze Nacht & Liebster, die ganze Nacht \\
\hline I have been flickering, off, on, off, on. & Hab ich geflackert, aus, an, aus, an. & Hab ich geflackert, aus, an, aus, an. & Hab ich geflackert, aus, an, aus, an. \\
\hline The sheets grow heawy as a lecher's kiss. & Schwer wird das Bettzeug wie ein Wüstlingskuß. & Schwer wird das Bettzeung wie ein WüstlingskuB. & Schwer wird das Betttuch wie ein LüstlingskußB. \\
\hline Three dayss, Three nights. & Drei Tage. Drei Nächte. & Drei Tage. Drei Nächte. & Drei Tage. Drei Nächte. \\
\hline Lemon water, chicken & Zitronenwasser, Hühner- & Zitronenwasser, Hühner- & Ztitronenwasser, Hühner- \\
\hline Water, water make me retch. & wasser, Wasser macht mich erbrechen. & wasser, Wasser macht mich erbrechen. & wasser, Wasser macht mich erbrechen. \\
\hline I am too pure for you or anyone. & Ich bin zu rein für dich oder irgendwen. & Ich bin zu rein für dich oder irgendwen. & Ich bin zu rein für dich oder irgendwen. \\
\hline Your body & Dein Körper & Dein Körper & Dein Körper \\
\hline Hurts me as the world hurts God. I am a lantern - & Schmerzt mich wie die Welt Gott. Ich bin eine Laterne - & Schmerzt mich wie die Welt Gott. Ich bin eine Laterne - & $\begin{array}{l}\text { Schmerzt mich wie die Welt Gott. Ich bin eine Laterne } \\
\text { - }\end{array}$ \\
\hline My head a moon & Mein Kopf ein Mond & Mein Kopf ein Mond & Mein Kopt ein Mond \\
\hline Of Japanese paper, my gold beaten skin & Aus Japanpapier, meine geschlagene Goldhaut & Aus Japanpapier, meine geschlagene Goldhaut & Aus Japanpapier, meine geschlagene Goldhaut \\
\hline Infinitely delicate and infinitely expensive. & Unendlich zart und auch unendlich kosibar. & Unendilich zart und auch unendlich kosibar. & Unendlich zart und auch unendlich teuer. \\
\hline Does not my heat astound you. And my light. & Erstaunt dich meine Hitze nicht. Mein Licht? & Erstaunt dich meine Hitze nicht. Mein Licht? & Erstaunt dich meine Hitze nicht. Mein Licht? \\
\hline All by myself I am a huge camellia & Ich bin allein und bin eine große Kamelie & Ich bin allein und bin eine große Kamelie & Ich bin allein und bin eine groBe Kamelle \\
\hline
\end{tabular}




\begin{tabular}{|c|c|c|c|}
\hline ORIGINAL & CORRECCIONES & 3. ${ }^{a}$ VERSIÓN (POSBBLE ENTREGADA) & 4. ${ }^{2}$ VERSIÓN (PUBLICADA) \\
\hline \multirow[t]{2}{*}{ Glowing and coming and going, flush on flush. } & Und glüh und komm und gehe, Flut um Flut. & Und glüh und komm und gehe, Flut um Flut. & Und glühe und komme und gehe, Flut um Flut. \\
\hline & I. (y en p. siguiente) (39.5 Fieber, Blatt 2) & I. (y en p. siguiente) (39.5 Fieber, Blatt2) & \\
\hline I think I am going up, & Ich glaub, ich gehe hoch, & Ich glaub, ich gehe hoch, & Ich glaub, ich gehe hoch, \\
\hline I think I may rise - & Ich glaub, ich könnte steigen - & Ich glaub, ich könnte steigen - & Ich glaub, ich könnte steigen - \\
\hline The beads of hot metal fly, and I, love, I & Die Rosenkranzperlen aus heißem Metall & Die Rosenkranzperlen aus heißem Metall & Die Rosenkranzperlen aus heiliem Metall \\
\hline Am a pure acetylene & Flegen: und ich, Liebster, ich & Fliegen; und ich, Liebster, ich & Fliegen, und ich, Liebster, ich \\
\hline Virgin & Bin eine reine Acetylen- & Bin eine reine Acetylen- & Bin eine reine Acetylen- \\
\hline Attended by roses, & jungriau, geleitet von Rosen, & jungrfau, gelètet von Rosen, & jungrrau, umkränzzt von Rosen, \\
\hline By kisses, by cherubim, & Von Küssen, von Cherubim, & Von Küssen, von Cherubim, & Von Küssen, von Cherubim, \\
\hline By whatever the pink things mean. & Von was immer diese rosa Dinger bedeuten, & Von was immer diese rosa Dinger bedeuten, & Von was immer diese rosa Dinger bedeuten, \\
\hline Not you, nor him & Nicht dir, noch ihm, & Nicht dir noch ihm, & Nicht dir noch ihm, \\
\hline Not him, nor him & Nicht ihm, noch ihm & Nichtihm noch ihm & Nicht ihm noch ihm \\
\hline (My selves dissolving, old whore petticoats) - & (Meine Selbste lösen sich auf, alte Hurenunteröcke) -- & (Meine Selbste lösen sich auf, alte Hurenunterröcke) -- & (Meine Selbste lösen sich auf, alte Hurenunterröcke) \\
\hline To Paradise. & Ins Paradies. & Ins Paradies. & Ins Paradies. \\
\hline
\end{tabular}

